\title{
The Space Between: \\ Transformative Public Space
}

By

\begin{abstract}
Anne-Marie N. M. Kasowski
A thesis submitted to the Faculty of Graduate and Postdoctoral Affairs

In partial fulfillment of the requirements for the degree of
\end{abstract}

Master of Architecture

\author{
Carleton University \\ Ottawa, Ontario \\ (C) 2019 \\ Anne-Marie Kasowski
}




\section{Acknowledgments}

I would like to thank my thesis advisors, Professor Yvan Cazabon, and Professor Roger Connah of the Azrieli School of Architecture \& Urbanism at Carleton University. My professors were always available when I had questions about my research or writing. They allowed this paper to be my own work, but steered me in the right direction whenever they thought I needed it.

I would also like to thank the guest critics and the other experts for their suggestions while participating in the many colloquiums, helping me develop my project and writing of this thesis.

In addition, I am grateful for the other master students, who where always there to inspire, and put a smile on my face.

Lastly I would like to thank John for the help of proofreading, and untangling my thoughts. 


\title{
Prologue - The Space Between

\author{
"To propose "empty space" in the \\ context of architectural design may \\ seem obscure, but is an empty space the \\ critical counterpart to the instrumental \\ consideration of space, which relegates \\ empty space to the category of a wasted \\ resource?" 1
}




\section{Abstract}

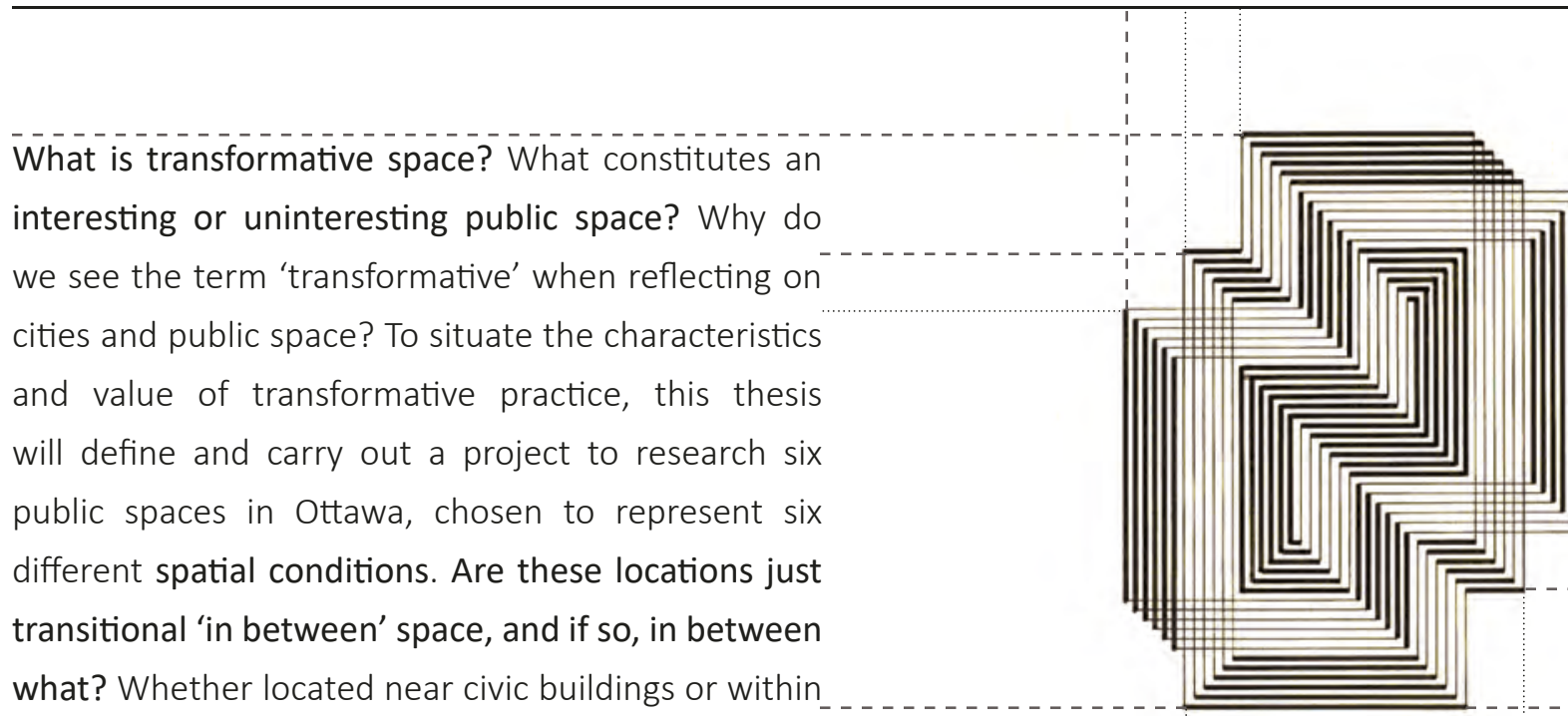

residential neighborhoods, what is the narrative

Figure 001 - Josef Albers, Blurred Lines we expect from a pubic space or wish to insert into it? These public spaces are constantly in transition. This thesis will explore the tensions between spaces by examining their adaptive and transformative qualities. The project, integrated within the thesis, will offer spatial strategies and interventions that explore the potential for spatial change as urban situations and human needs evolve.

The spatial strategies and interventions proposed for each of the distinct spaces will result in a site specific alteration of current conditions. The impact of alterations will tend to result in both quantitatively measurable improvements such as providing an increase in access to or between spaces and qualitative enhancements such as presenting a greater sense of openness or more pleasant surroundings. The qualitative enhancements may be interpreted positively or negatively, and are subject to the perspective of each person interacting with the space. 


\section{Project Description}

Six public spaces within the city of Ottawa are identified and examined within this document. Each public space characterizes a different situation in the city contributed to, in part by differing spatial conditions. The project will examine the narrative we expect from a space; wish to insert into a space; what is currently in the space, and how these interactions might affect the surrounding area. Most public spaces are constantly in transition for a variety of reasons; two main factors that contribute to the transition of a space are the municipal by-laws and the needs of the local inhabitants. Public spaces cannot just be thought of as a static three dimensional arrangement of material; a fourth dimension of time must be considered in each of the six spaces under examination. Time affects space, whether that is from the changing needs of the surrounding inhabitants due to alterations in demographics or changes in attitudes and priorities in the general population. Even the impact of time on the vegetation and the decay of infrastructure within the space are both factors to consider. Tensions in the existing public spaces will be adapted and transformed into something new by offering spatial strategies and/or interventions that explore the potential for temporal and spatial change as urban situations evolve. 


\section{Table of Contents}

\begin{tabular}{lr} 
TITLE & i \\
\hline ACKNOWLEDGMENTS & ii \\
PROLOGUE & iii \\
ABSTRACT & iv \\
PROJECT DESCRIPTION & $\mathrm{v}$
\end{tabular}

\begin{tabular}{llr}
$\mathrm{CH} 1$ & $\mathbf{1}$ \\
\hline & INTRODUCTION TO CONCEPT & 5 \\
USE OF SPACE & 7 \\
THE SPACE BETWEEN & 10
\end{tabular}

\begin{tabular}{lll}
$\mathrm{CH} 2$ & $\mathbf{1 2}$ \\
\hline & SITES & 13 \\
CITY OF OTTAWA_SITES & 14 \\
CONNECTIVITY WITHIN THE CITY_SITES & 16 \\
TYPES OF SITES & 17
\end{tabular}

CH 3 PROPOSED NARRATIVES AND INTERVENTIONS 32

TYPES OF DEVICES 33

PROPOSED NARRATIVE AND INTERVENTION [X6] 34

\begin{tabular}{ll} 
EPILOGUE_POSTSCRIPT & $\mathbf{5 2}$ \\
\hline PROJECT EVOLUTION & 52
\end{tabular}

APPENDIX_INSPIRATIONAL PROJECTS OR PLACES 58

APPENDIX_INSPIRATIONAL IMAGES 62

APPENDIX_INTERESTING AND RELATED PRECEDENTS 64

LIST OF ILLUSTRATIONS 66

ENDNOTES $\quad 70$

$\begin{array}{ll}\text { SOURCES } & 72\end{array}$ 


\section{1- Introduction to Concept}

Term List

In order to study transformative public space and its relationship to 'The Space Between' there are several key terms that need to be defined. Understanding the intricacy of these terms, forms a foundation to allow for the exploration of 'The Space Between'.

Transformation occurs when a condition or physical element changes from one state to another. Some conditions can be transformative, where a marked change occurs and the resulting transformation becomes constant, affecting the surroundings and supporting continued transformation from a new level. "Transformation can be radical or incremental, it can be sudden or gradual, but (as most definitions tell us) it will eventually result in a marked change of appearance, usually (according to the more optimistic texts) for the better." 2

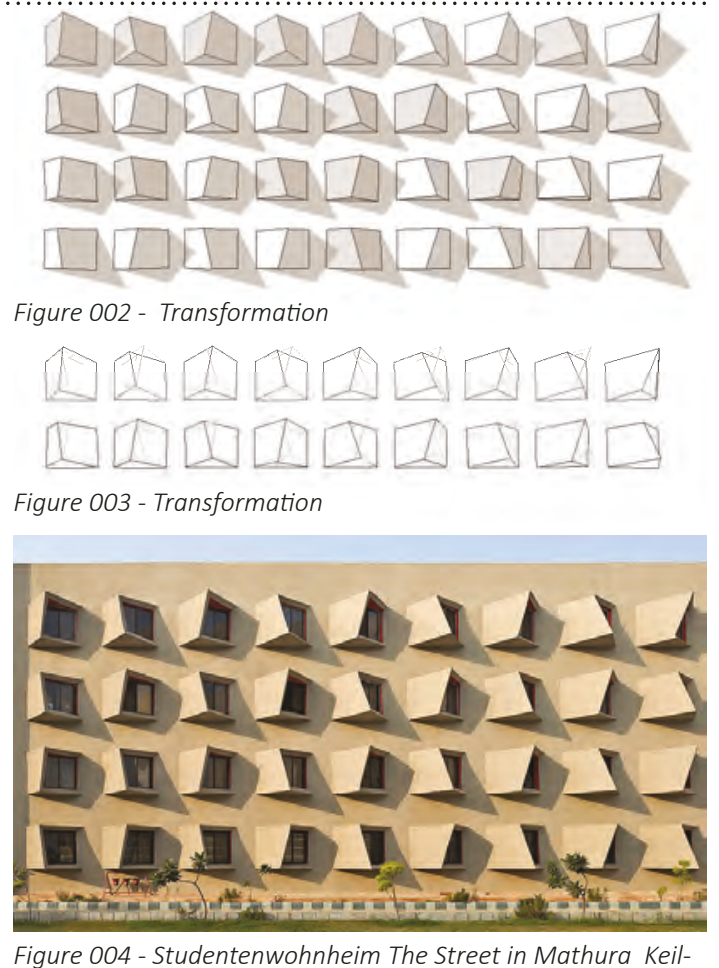

Figure 004 - Studentenwohnheim The Street in Mathura Keilförmige Fenstererker mit Nordausrichtung - Image of Building 
Transformation can be something broad and specific at the same time; it is a concept of change, and change can become anything including: "The ways people live in a city; the ways people imagine a city, the ways people articulate and inform a city, the ways people resource a city and the mapping of transformations of a city (Forcault 1994:138)"3

Public space can be defined in three major ways. When trying to define public space, or types of public space "we are left with: open only accessible spaces; spaces of common concern (by using common resources and having common effects); in spaces used for the performance of public roles." 4 There are also various levels of "publicness'. There are spaces that are public at all times of the day, which are used by the people of the city. Then there are spaces that are surrounded by businesses, and residents that utilize the space as their own, creating a space that is more semi-public than public. There are other spaces PUBLIC

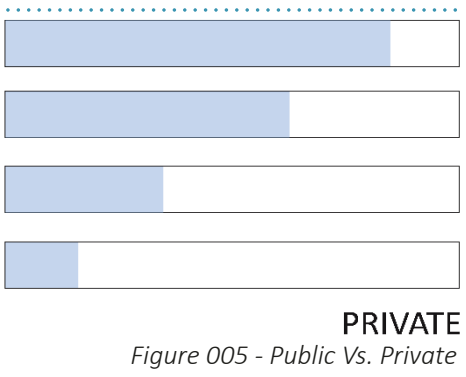
that do not stay open all the time. Some spaces may have set hours; others may be open to the public only during certain times of the year, day, or week. 
There are also spaces that, by all accounts, are defined as private but are used in functions that benefit the public as a whole. These variations in availability and use may blur the definition of public and private urban spaces. There are also variable ways that people use public space. How people use the space helps to define the criteria the space needs to satisfy functions deemed successful. "Outdoor activities in public spaces can be divided into 3 categories, each of which places very different demands on the physical environment: necessary activities, optional activities, and social activities." 5

Certain public spaces may be intended for specific activities such as to supply working areas for a public labor force or to provide a location to preform a necessary service. By contrast, a public space may also be used for optional or unplanned activities, whereby people spend time engaging in arbitrary activities purely for the enjoyment of doing so. These arbitrary activities include performing an action that doesn't specifically need to be set in a certain area, such as reading a book or feeding the birds. Lastly, social activities may occur in a space where people can meet others; it greatly depends on the ability for a space to encourage the presence of others. 
Term List

Adaptability is the built-in ability to adapt and adjust to change by accommodating different uses, allowing various spatial and functional configurations, and updating technologies without requiring significant disruption of the building, the ongoing activities within, and the environment. Just as a person could be thought of as adaptive, so could a space.

Interventions are modifications that can be made to an area, or situation. Normally interventions are introduced in order to update or improve

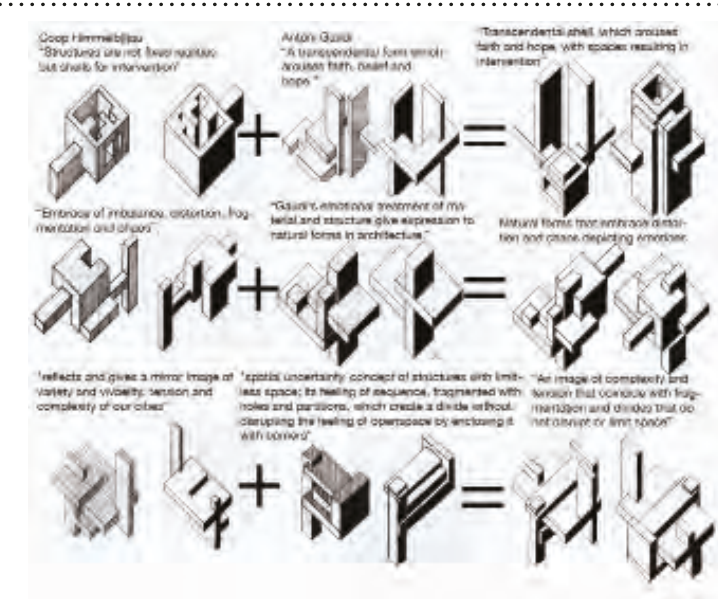

Figure 006 - George Mikhail, The 18th Sketch Axonometric elements. For example, technology could be introduced to provide better functionality, or just because the current condition is in a state of disrepair and the former functionality needs to be restored. As our community changes we need to take into consideration that what was once good might not be so in the current time or place. The evolving needs of the community will dictate the degree of intervention required. When looking at the different devices to improve a space, one needs to see how a space can be put to its best use and what the design criteria is for a specific time and place. There are external influences that will have an impact on 'The Space Between'. In order to identify the optimal interventions intended for the space, the impact on the space arising from these external influences must be considered. 


\section{External Influences on Urban Space}

External Influences

Seasons are one of the Earth's natural systems which divide the year into a cycle of four periods: spring, summer, autumn, and winter. Each season is marked by the amount of daylight hours resulting from the earth's changing position with the sun, and can also impact the weather depending on location. Seasonal spaces do not only refer to yearly changes; they could also reflect daily, monthly, and weekly changes. Such changes impact the potential uses of a space. There could be office workers scurrying through the space during the weekdays, and families spending leisure time relaxing or socializing during the weekend. Any intervention applied to the space may need to adapt to mitigate the impact caused by differences in patterns of use during the year, week, or day.

Nodes within a city can be described as important functional points, or intersections of functional zones. Nodes may include functional points for transit, shopping, government, and other specific concentrated activities. Nodes are the intersection points that help the city continue to function. The type of node and proximity to the space will impact the desired uses for the space. Any new architecture interwoven within a space must consider nodes. 
External Influences

An Ephemeral space is one that is constantly changing and re-invented. Devices used to create an ephemeral space include Pop - Ups which is a term that is applied to something that is easy to assemble and disassemble, that may change a space to create something new or different. Other devices include Open Street, where by restricting vehicular traffic provides access to the whole road resulting in a space that could adapt to different public events. Also, an Interim Public Plaza could result from inexpensively dressing up an underused paved area.

The Society of a space refers to the people and community in the surrounding area. Local people are always great influencers of a space. To most social scientists it has always seemed self-evident that "it is surely society that determines space and not space that determines society. The approach to the city that this generates is one of trying to see the spatial environment as the spatial output, and so as the by-product, of social, economic and perhaps cognitive processes." ${ }^{16} \mathrm{Ar}-$ guments can be made that space influences society and equally strong arguments can be made that society influences space. The arguments are not binary, it is possible, and more likely that society and space influence each other.
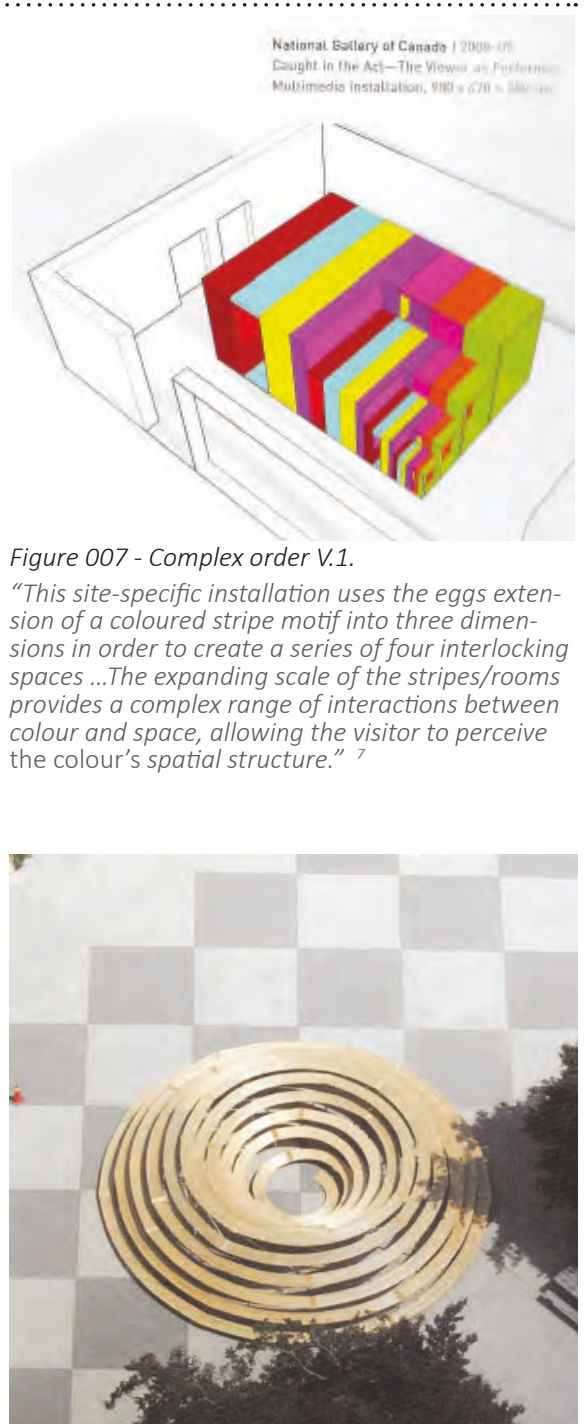

Figure 008 - Complex order V.2.

"Through this simple diagram it is possible to sit looking inward towards one another or outward to the surrounding city. MPS (speaker) is composed of two parts, a continuous wood surface in the steel scaffold of connected points. The surface acts as essential definition of space, providing places for seating or standing at various elevations." 8 


\section{Use of Space}

What qualifies as 'good' space?

Classifying a space as 'good' is dependent on the opinions of those people using the space. Individuals tend to have distinct perceptions of what 'good' space is. There may never be unanimous consensus among any group, especially if they have competing needs.

The best uses of a space can have many definitions, and can mean different things to different people. The primary best uses criteria applied to form the spatial strategies and interventions for the six public spaces under consideration reflect how the use is most functional for the surrounding community, encouraging people to make use of the space. These are elaborated in the program description for each design strategy.

A wasted space might be described as an unappealing, non-functional, inconvenient space, or a mix thereof. In a growing and vibrant city, a space that might provide sought after functionality but does not, is considered an underused or wasted space. The key to site improvement is increased inhabitation. If changes applied to a space result in no increase in human activity then those changes should not be considered an improvement.

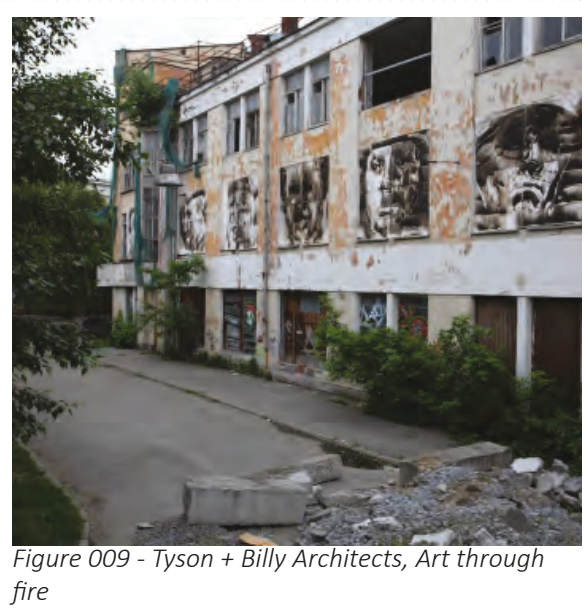


Habitation of public space creates a form of contact between people in an informal relaxed way. Public spaces may be accessed by all people, "regardless of ethnic origin, age or gender, and as such they represent a Democratic forum of citizens in society." Public space allows an otherwise diverse set of people to realize what they have in common, "they bring communities together, provide meeting places and foster social ties of a kind that have been disappearing in many urban areas." Public spaces help to define an area from a cultural perspective and "provide a sense of place for local communities." ${ }^{\prime \prime}$

A space tends to form common bonds with those that use it, often without being apparent at the outset. Common experiences like walking along the same tree-lined shaded path, or appreciating a specific sculpture or other art, provide a common frame of reference for the inhabitants and thereby are reflected in - and help define - the community.

Multiple - Uses within public spaces support interactions within the community in ways specific to the needs of the neighboring group using the space.

"Constructions they offer multiple variable perspectives, and therefore a greater insight into the nature of building itself. We might say its works are not "used up" in their functioning, but always leave difference as a reminder." 10 
What qualifies as 'good' space?

Through the flexibility of use, a site intervention will not only address the immediate space and its requirements, but also the needs of its surroundings, thereby creating a more inter-connected set of spaces throughout the city. Multiple-Uses can be thought of as distinct layers or dimensions within the same common space. What does it "mean to form and transform places we inhabit? Is transformation something that just happens in the collective processes of daily lives? Do we set out to transform urban environments with active intent? "11

Transformations of space may be passive, such as the formation of a path between two points over time, or a they may be created through active intent or intervention. Exploration of 'the space between' will touch on the passive as an initial condition and emphasize 'good' actively planned interventions that satisfy the key indicators of increased inhabitation and an ability to provide for multiple uses. 


\section{The Space Between}

What does the space between really mean?

The space between can be defined in many ways, and may include spaces between buildings, spaces between functions, and void spaces within a dense urban fabric. When accessing the space between, we should not only consider a single perspective to identify the best attributes and the unfavorable attributes. When multiple perspectives are considered in a proposal the result will maximize the net benefit to the most inhabitants and users of the democratized space.

Whether a subject area is empty, busy, or a condition in between, spatial strategies and interFigure 010 - City Square ventions should, for the most part, reflect on the situation, and the needs of the surrounding community. Tuset suggests that "the most admirable aspect is what remains in the memory of people and it is generally 'Not the buildings but the space between them'. ... the value and pleasure of the daily life that appears just making good use of the site." 12 The space between may act as a frame on the adjacent space, or it may act as a transition from one space to another.

'The space between' may even provide a sense of experience that is lacking in the adjacent space, but which is greatly missed by its users. Perhaps a small patch of calm, nature and greenery adjacent to busy urban settings will provide a sense of balance and complement the adjacent space. 
Depending on the nature of the spaces, and the benefit derived from each, some may develop a reversed perception and think of the original adjacent space as the space between and the new reworked space between as the focal area.

Thresholds between spaces help to define either side while providing clear limits. By managing thresholds we can create an interesting transitional condition while allowing for separations as well as connections between identifiable spaces. A threshold could be a subtle way to separate spaces or could be a more defined strategy meant to articulate the in-between as a liminal condition.

A Liminal condition exists in time and space. It is a state of limbo - the time between what was and what will be. It is a space in transition, from what is known to that which is waiting - the unknown that is about to happen. Such conditions may be uncomfortable, awkward and unsettling or they could be dramatic, intense, transitional and hopeful. The design proposals will ensure that the liminal condition is enhanced and used in a constructive way. 'The space between' should be a complementing transitional space which is inviting, comfortable, and pleasant, but still present a threshold where warranted - a moment of anticipation and excitement. 


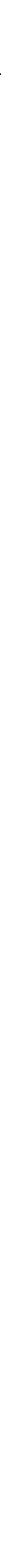




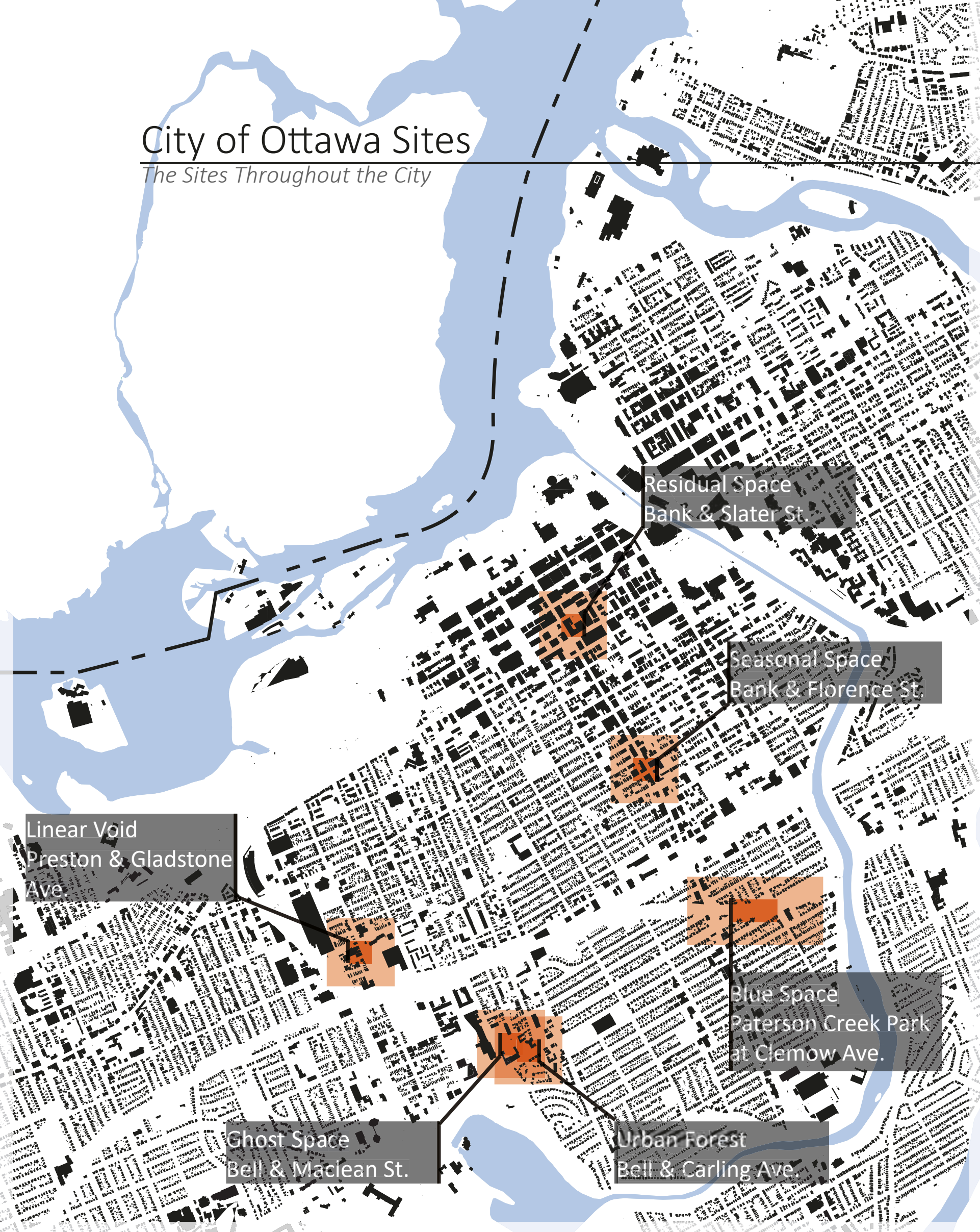




\section{Connectivity Within the City}

Spatial Conditions of the Sites

The six public spaces - subjects of this analysis - were examined for their unique spatial conditions. All of the sites can be described as 'the space between', while their unique characteristics can be described as follows:

The Preston and Gladstone site takes the form of a narrow alley way. The Bell and Maclean site is an abandoned odd shaped space of varying elevations. At Bank and Florence there is a pedestrian shortcut between two adjacent areas that gets intermittent use with some periods of high traffic. The Bank and Slater site is an underutilized dead end. A pond of water exists at the Paterson Creek Park and Clemow site, however elevation changes cut it off from the surrounding area. Finally, the Bell and Carling site is abandoned and overgrown with vegetation.

All of these sites can be identified as wasted space since they are basically unappealing, non-functional, or have inconvenient access. However, there are also differences between the spaces characterized by their distinct physical features and uses as described by the words narrow, abandoned, intermittent, underutilized, water, and vegetation. 
Distinctive interventions can be applied to each of the sites, taking advantage of and leveraging the unique spatial conditions and physical features of each space to create a new narrative that will resonate with the adjacent spaces and the population that would use each of the six public spaces. The key to site improvement is increased inhabitation. It may be possible to turn 'the space between' - a set of adjacent spaces - into the focal point.

Each of the six distinct spatial conditions under examination are described in the following pages followed by an assessment of how they are exhibited and applied in each site. 


\section{Types of Sites}

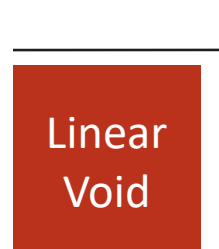

Linear voids normally consist of a long narrow space, taking into

A Narrow consideration not just horizontal but vertical space too. Examples Height

\section{Void} of linear space include water ways, shorelines, railways, highways, alleys, and connected parks.

Ghost
Space

Ghost space is generated by fragments of urban planning which never fully materialized. It is a place that lives, constantly in a state of dislocation, possibly abandoned.

Cut Through

Seasonal
Space

Seasonal space tends to be overcrowded and overexposed places which become semi-abandoned and lethargic spaces, and which are repeatedly reanimated in short cycles. They experience a lack of definition, a transition between some-place and no-place.

Dead End

Residual
Space

Leftover space that has been under-utilized which can be improved through intervention.

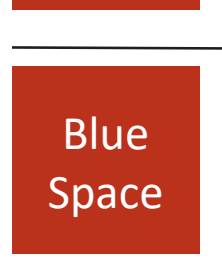

Connectively A space with anything to do with water including, water features, ponds, lakes, fountains, rivers, and water ways.

Abandoned 

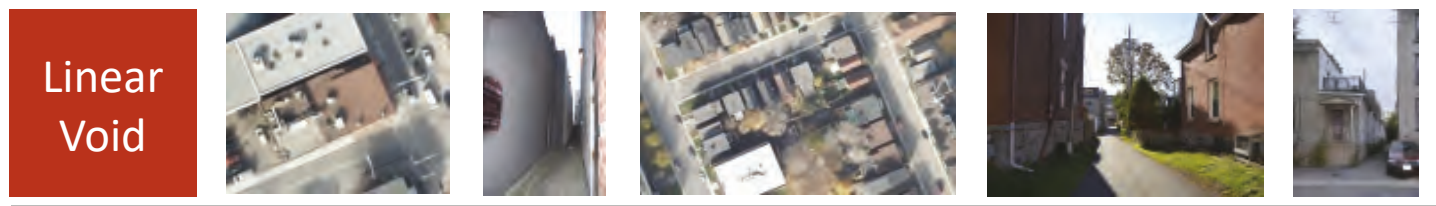

A Narrow Height - Current Narrative and Site Overview

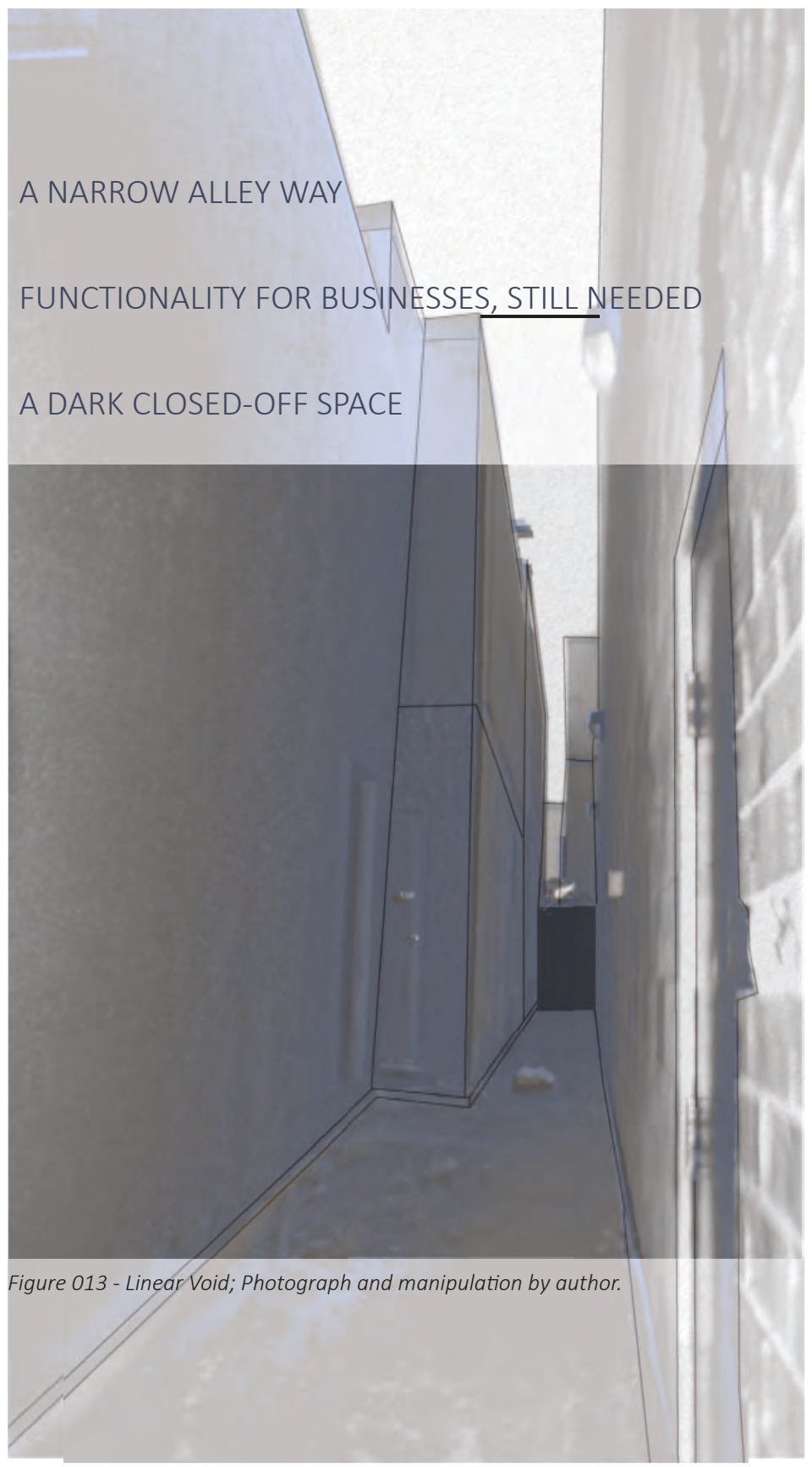

A linear void usually presents itself as a long, narrow, and sterile space with no obvious reason for being other than to signify a division between adjacent spaces or properties. The degree of narrowness can be emphasized by height. The void extends not only forward and backward, but also extends in a second dimension, from the point of the observer upward to the sky. Essentially the upward extension may appear infinite as the sky, restricted by the sides of the void, makes it appear as the void has no end. In contrast to the seemly infinite expanse of the up dimension and the forward dimension, the third side-to-side dimension is very finite, almost non-existent relative to the first two. The resulting restriction of movement by the observer when in the void becomes unsettling. 


\section{Linear \\ Void}
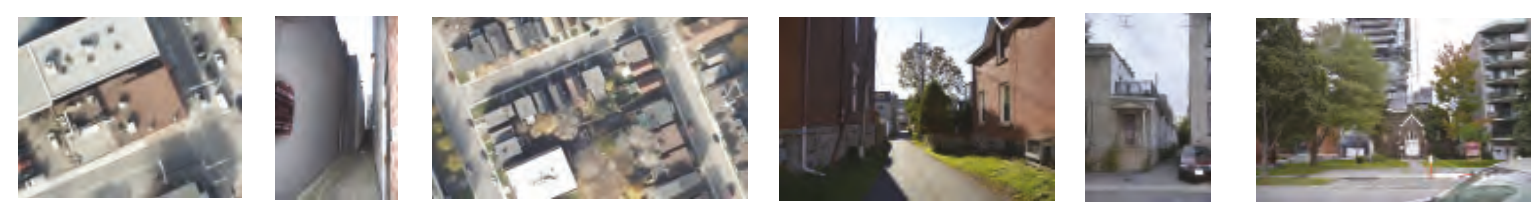

A Narrow Height - Current Narrative and Site Overview

The occupant cannot fly upward, are restricted on the sides, and can only proceed on a long journey forward or turn around. Once approaching the halfway point, the anxiety level of the occupant may rise as the realization that the option to turn back is just as daunting as the option to proceed forward. Only once nearing the end, relief starts to materialize.

The site, located near Preston Street and Gladstone Avenue, is an alley between two buildings; Preston Hardware and Trattoria Caffè Italia. There are a number of other businesses, including shops, restaurants, cafés, and a few residential homes coming off Preston Street. This is an shared awkward space.

A barrier prevents access to exit the alley at the far end. There is access to a business on one side of the alley and two access points to a business on the other side, including an external electrical panel and venting ductwork. There is a brick and cement block wall on one side of the alley and the other side is coated with concrete plaster. Both walls are two stories in height. 

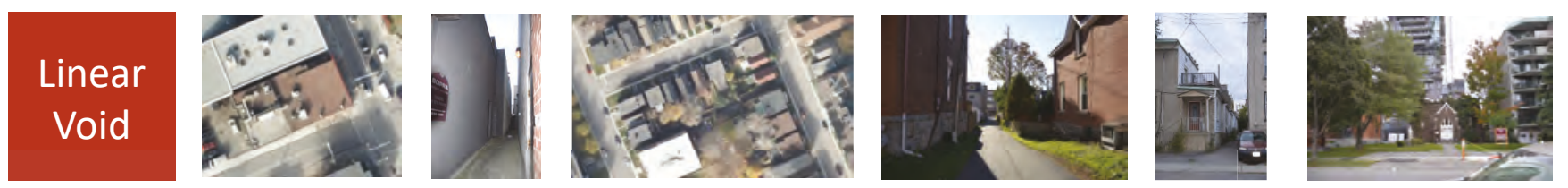

A Narrow Height - Current Narrative and Site Overview

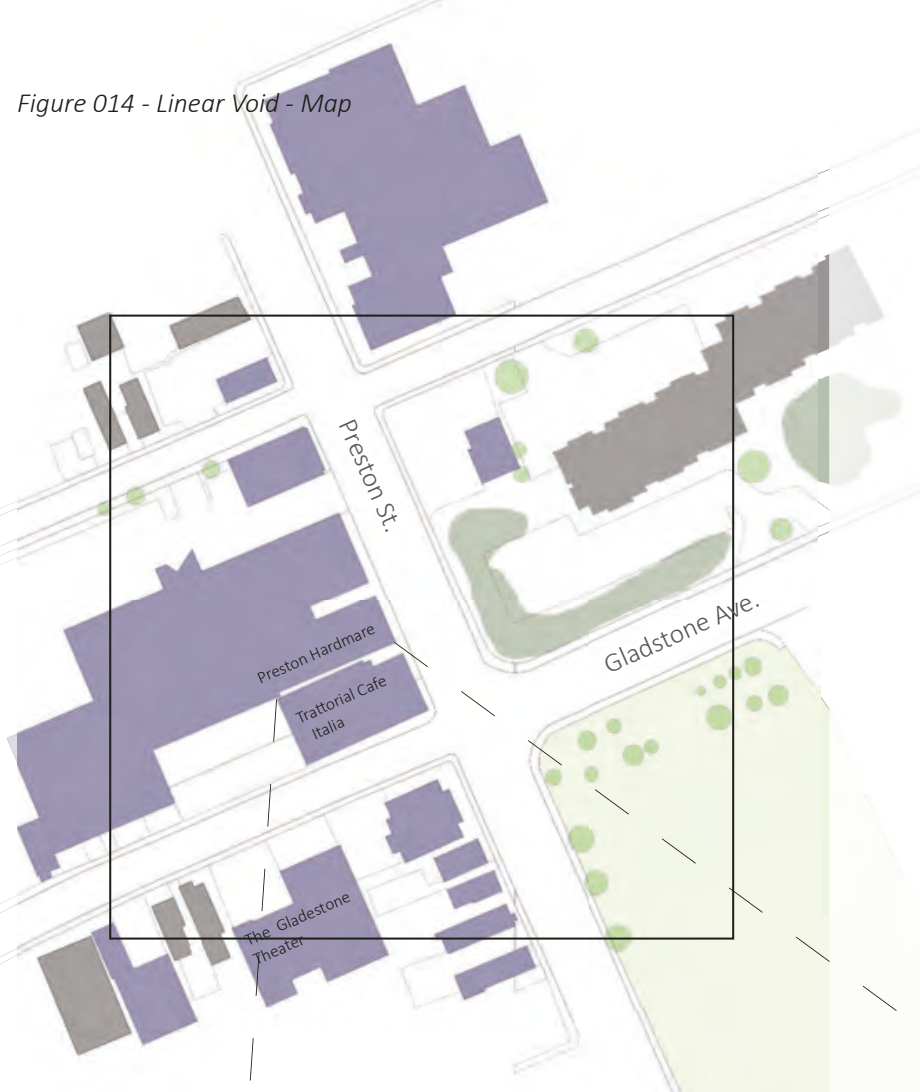

The expanded view, shows the alley space between buildings.

When addressing the obstacles, any intervention must respect the constraints to improve the overall narrative. The alleyway is narrow and gets narrower part of the way down due to the adjacent structure.

The primary obstacle is the narrowness of the space with walls of disproportionately extreme height on both sides. This site characterizes a linear void, by defi-

Residentia Businesses
Soccer_field

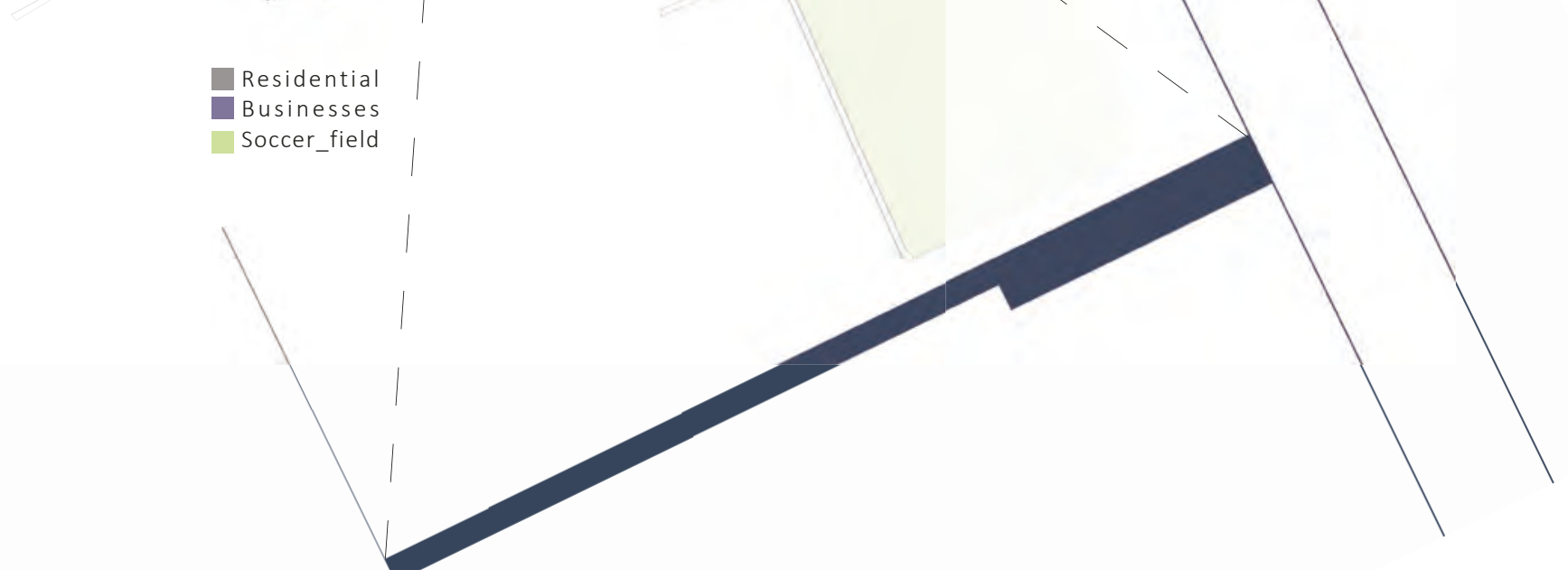




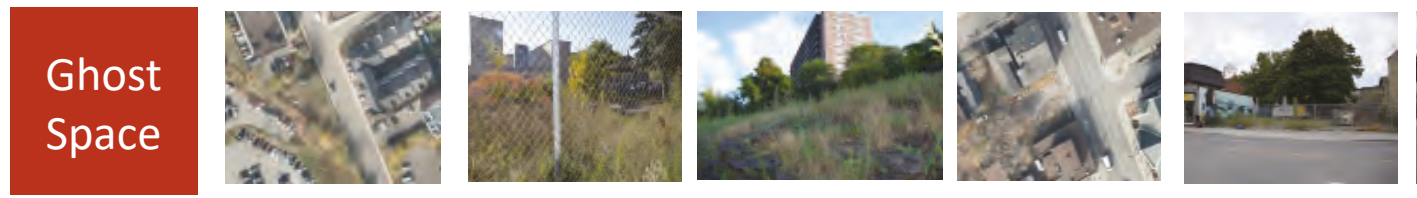

A Vertically Challenged Site - Current Narrative and Site Overview

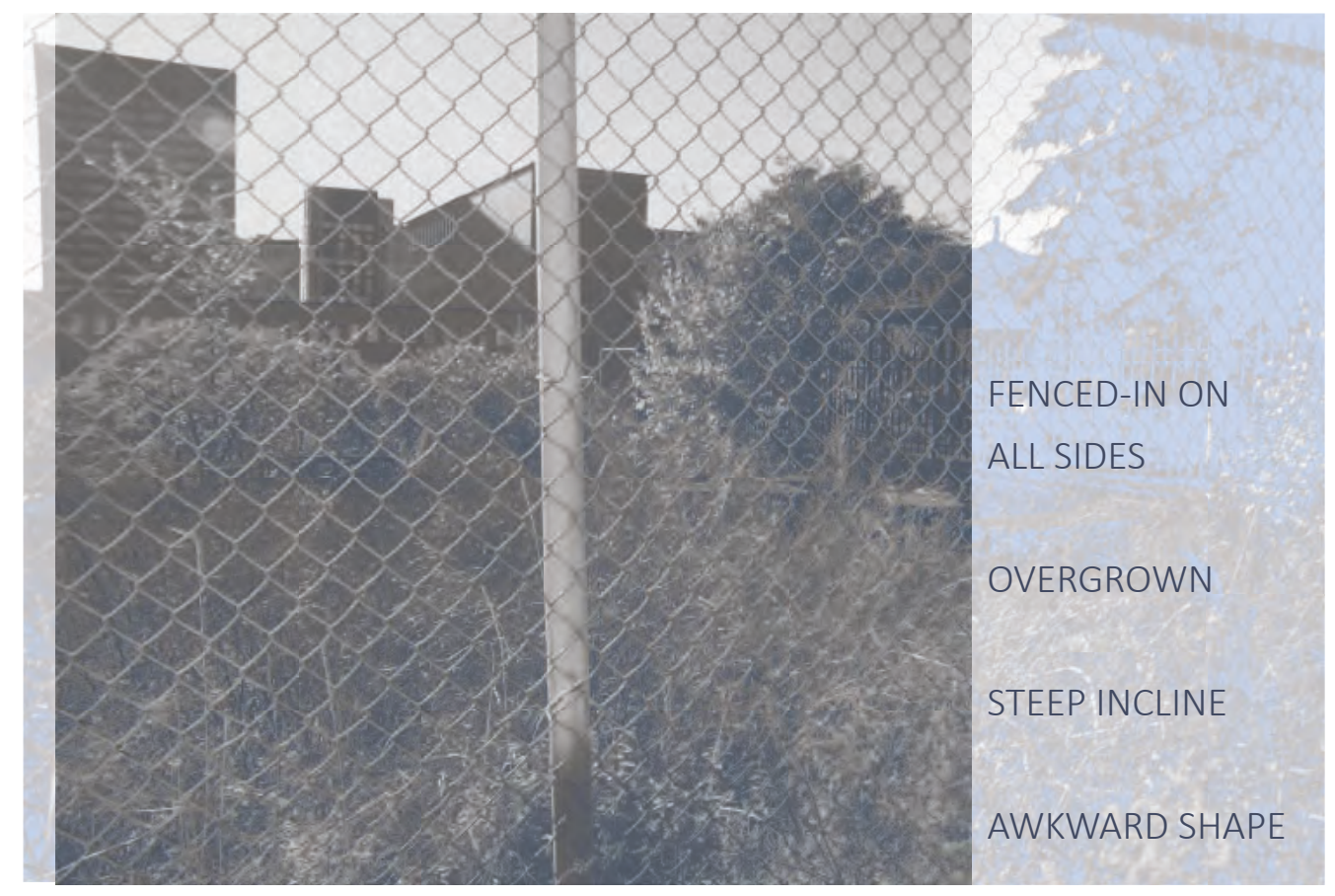

Figure 015 - Ghost Space - Photograph

Ghost Spaces are generated by fragments of urban planning which never did fully materialize. It is a place that lives, constantly in a state of dislocation, possibly abandoned.

This site, near Bell Street South and Carling Avenue is part of an adjacent government owned property, however cut off from it due to differences in elevation. The site is irregular in shape with a sleep incline up to a smaller flat area next to the street. Not only are the site dimensions and elevation awkward, the site is in an abandoned state. This neglected condition is re-enforced and made 


\section{Ghost}

Space
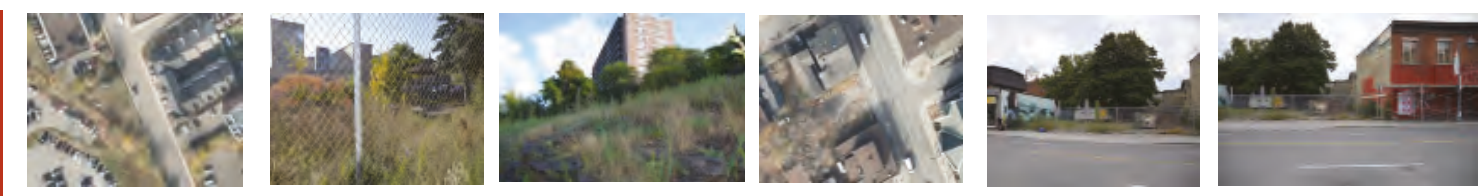

A Vertically Challenged Site - Current Narrative and Site Overview

to persist due to the chain-link fence surrounding the site.

There is an apartment building adjacent to the site and another across the street, with low residential structures mixed in. The space between this residential area and a grouping of government buildings is cut off from the main street, not only by the elevation difference, but also by the old chain-link fence surrounding the space.

Due to the obstacles, there is no access into the site and it has remained unused and forgotten for years as exhibited by the overgrown vegetation throughout. This ghost space is not only effectively invisible, it also cuts off any connection between the street and the lower area. 


\section{Ghost
Space}
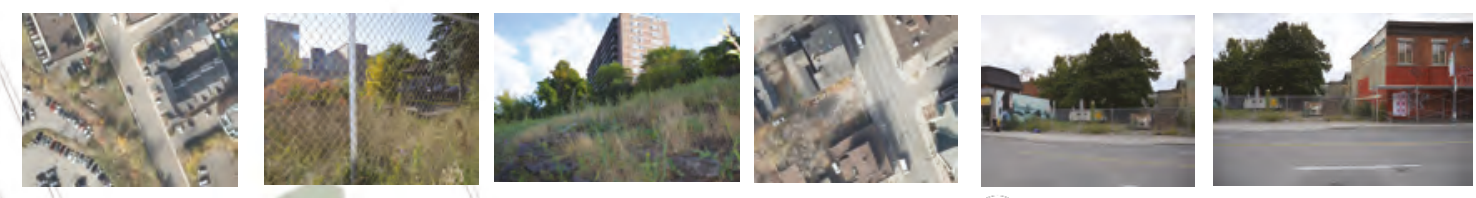

A Vertically Challenged Site - Current Narrative and Site Overview

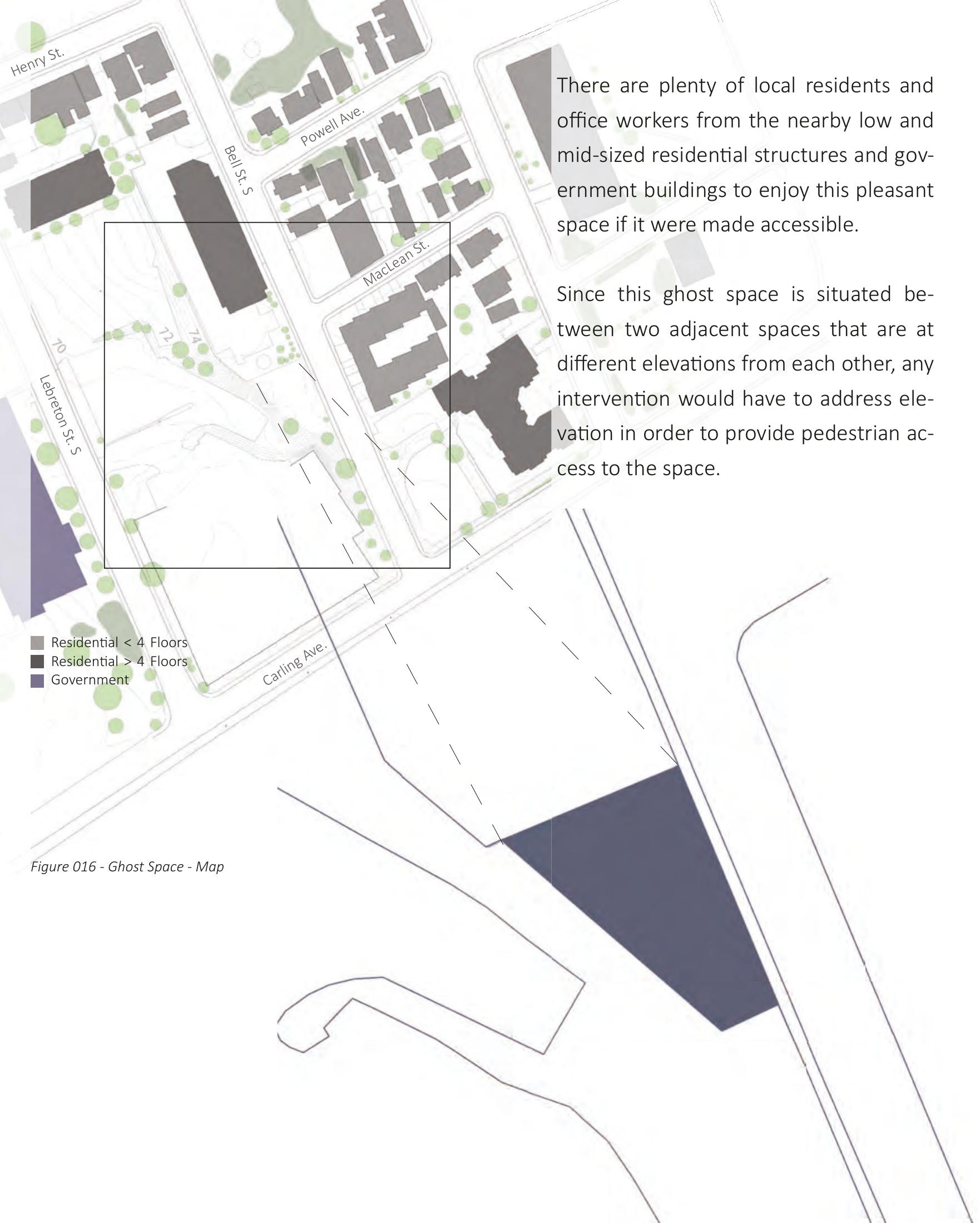



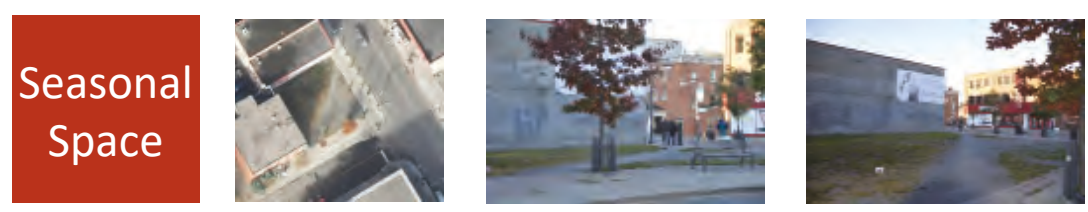

Cut Through - Current Narrative and Site Overview

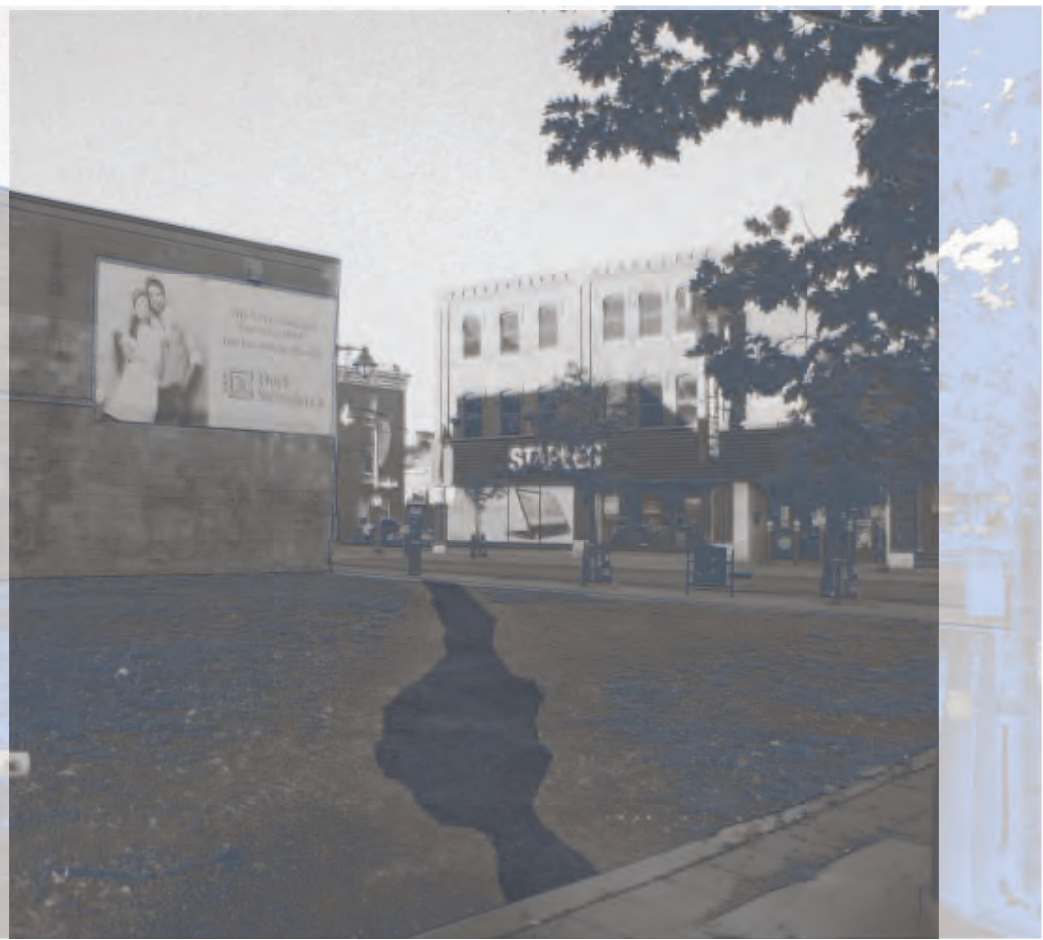

IN USE AT DIFFERENT TIMES OF DAY

A PLACE TO GO THROUGH NOT TO STAY

UNINVITING

Figure 017 - Seasonal Space - Photograph

Seasonal Spaces tend to be overcrowded and overexposed places which become semi-abandoned and lethargic spaces. Often, they are repeatedly reanimated in short cycles. They experience a lack of definition, a transition between some-place and no-place.

This site, a simple flat surface in the shape of a square on a corner, is desolate and uninviting. However, it has one feature, an informal path, that attracts many people for a very short period of time. People arrive at various frequencies depending on the amount of pedestrian traffic in the area. People do not linger on the site, it is simply a diagonal shortcut from one street to another. 


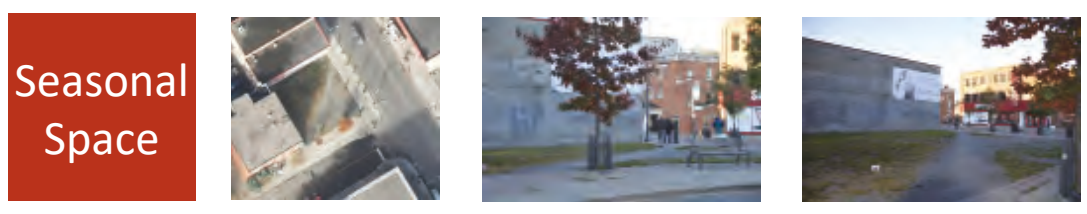

Cut Through - Current Narrative and Site Overview

The site is used at different times of day, sometimes busy other times it is completely empty, going from crowded to abandoned. When transversing the site there is nothing to look at to make the journey through pleasurable. It provides easy access and exit, a short-cut to save time. This space between has no substance.

Located on the corner of Bank Street and Florence Avenue, this empty lot or space between is not a barrier, but is used as a cut through by pedestrians. There are a number of businesses on Bank Street as well as several residences on the adjacent streets. The primary constraint is the uninviting nature of the site. The site is edged on two sides by two intersecting walls which are currently being used for advertising. 

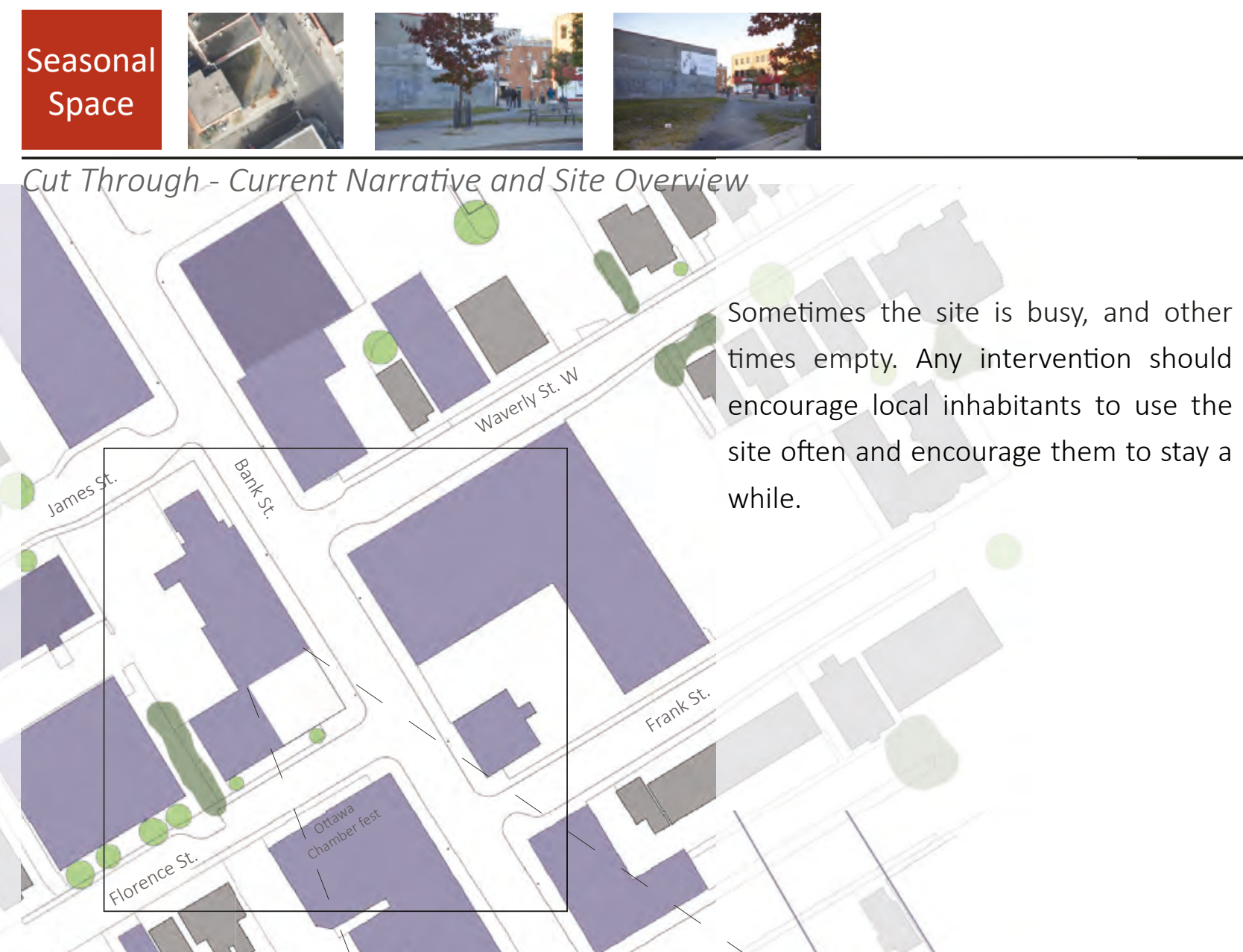
while.

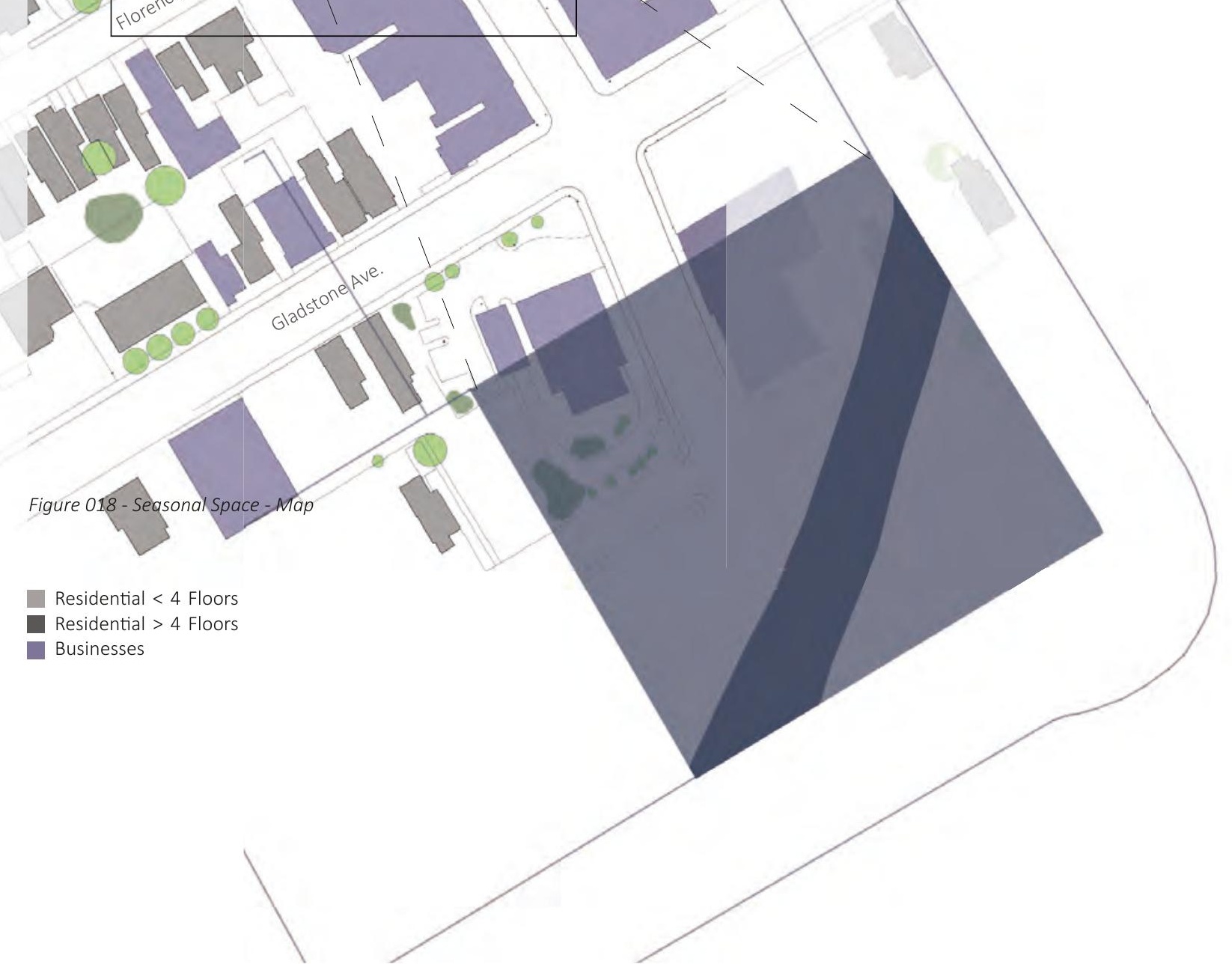




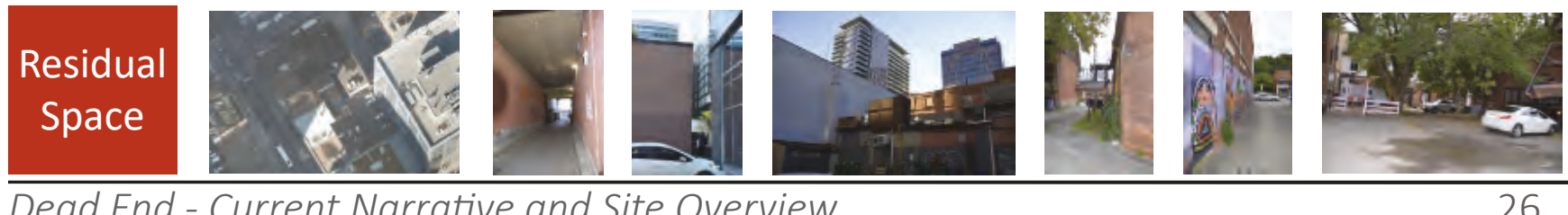

Dead End - Current Narrative and Site Overview
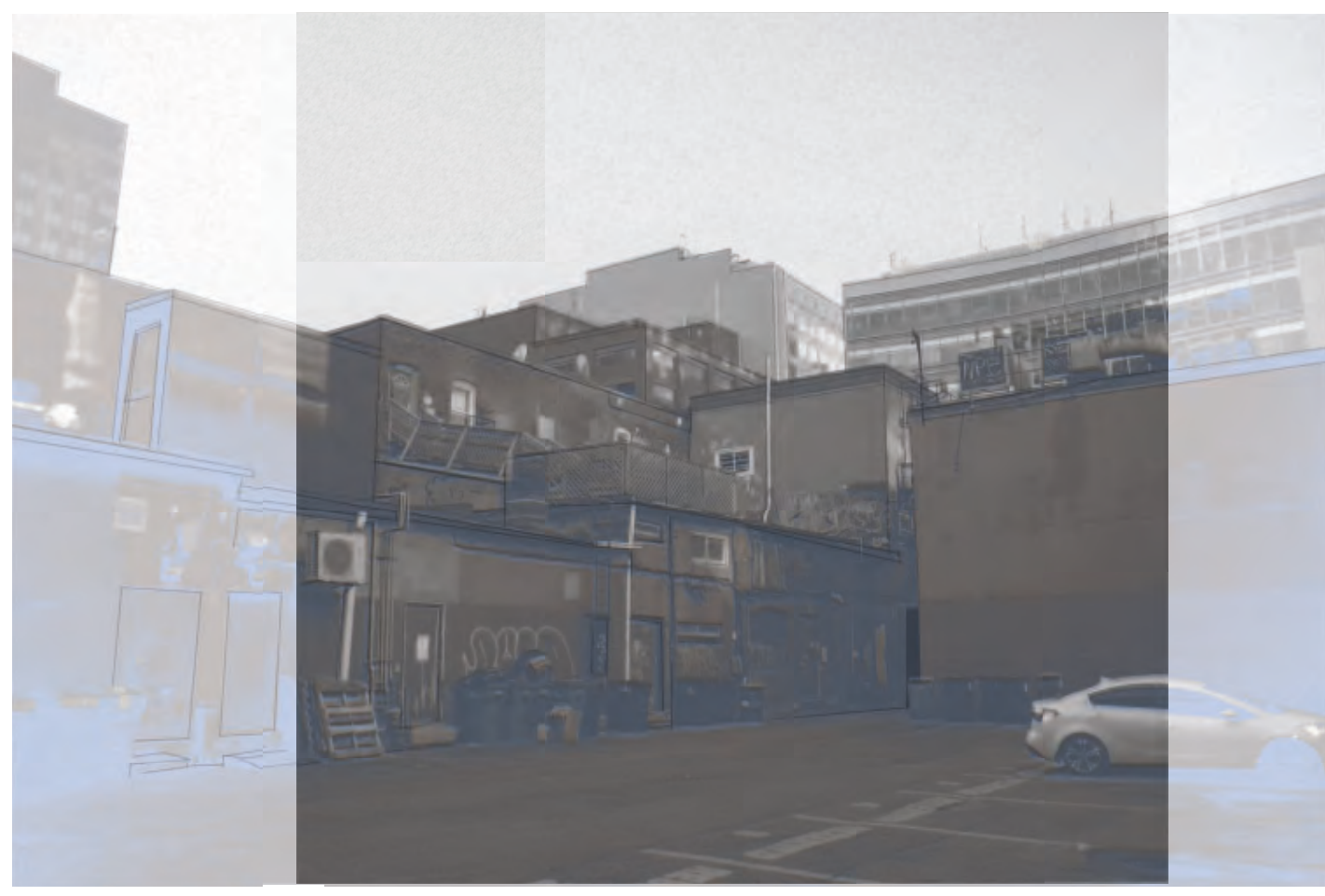

SURROUNDED BY BUILDINGS, DEAD END

MULTI-FUNCTIONAL

BACK OF SHOP

Figure 019 - Residual Space - Photograph

Residual Space can be defined as a leftover space that has been under-utilized which can be put to better use.

This dead-end site has a single vehicular and pedestrian entrance through a one storey tunnel cut out of the surrounding two storey businesses. At the end of the tunnel there are shop backs and garbage areas for a number of businesses fronting on Bank Street. It is an open but private space. The space expands to a parking lot which usually remains empty. Garbage bins and other materials are set against the back walls of the shops and businesses. Walking through the space is somewhat unsettling and uninviting due to the deserted and unkempt nature of the space. 


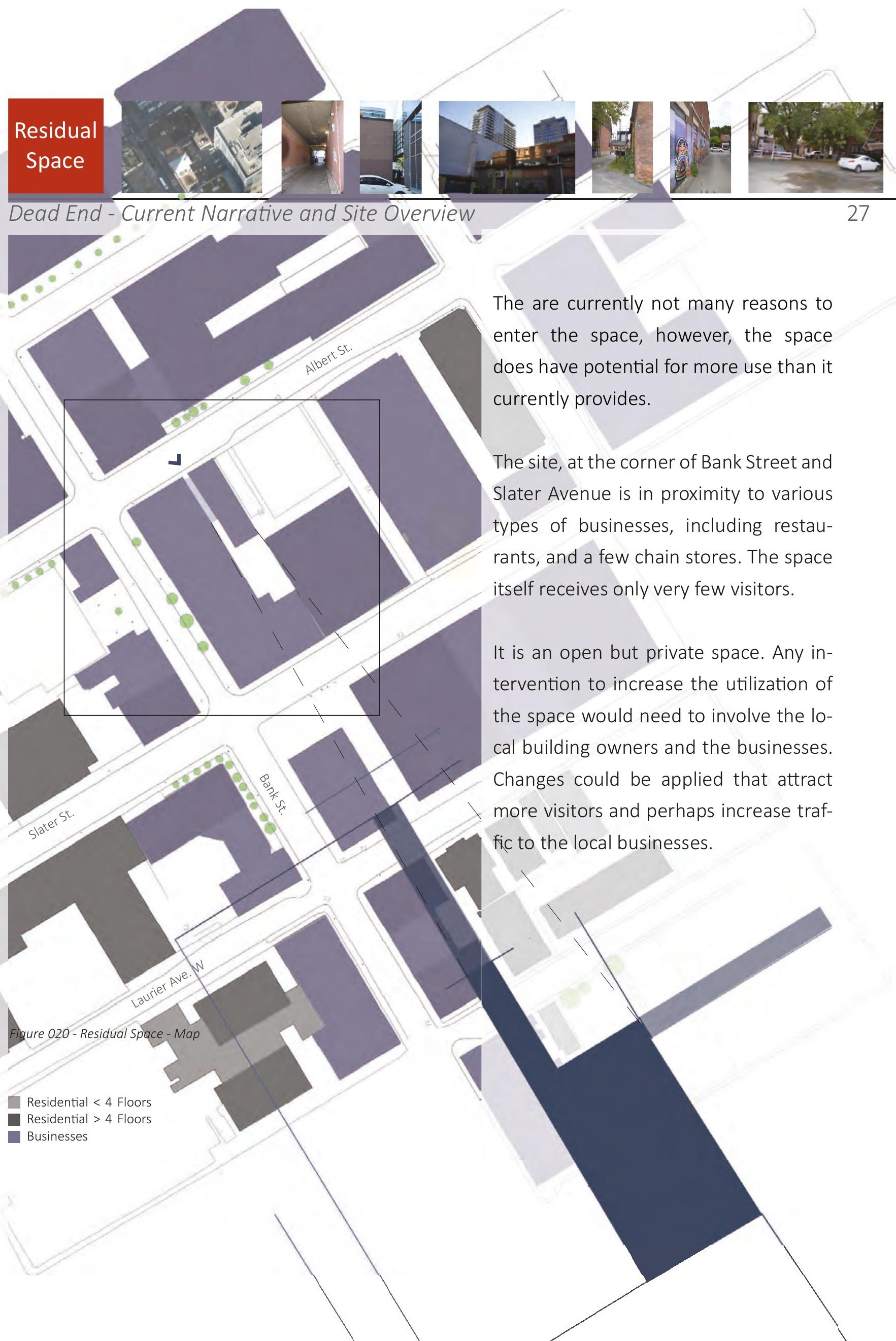




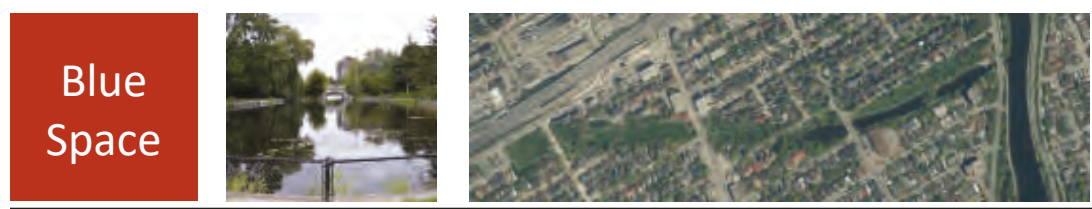

Connectively Challenged - Current Narrative and Site Overview

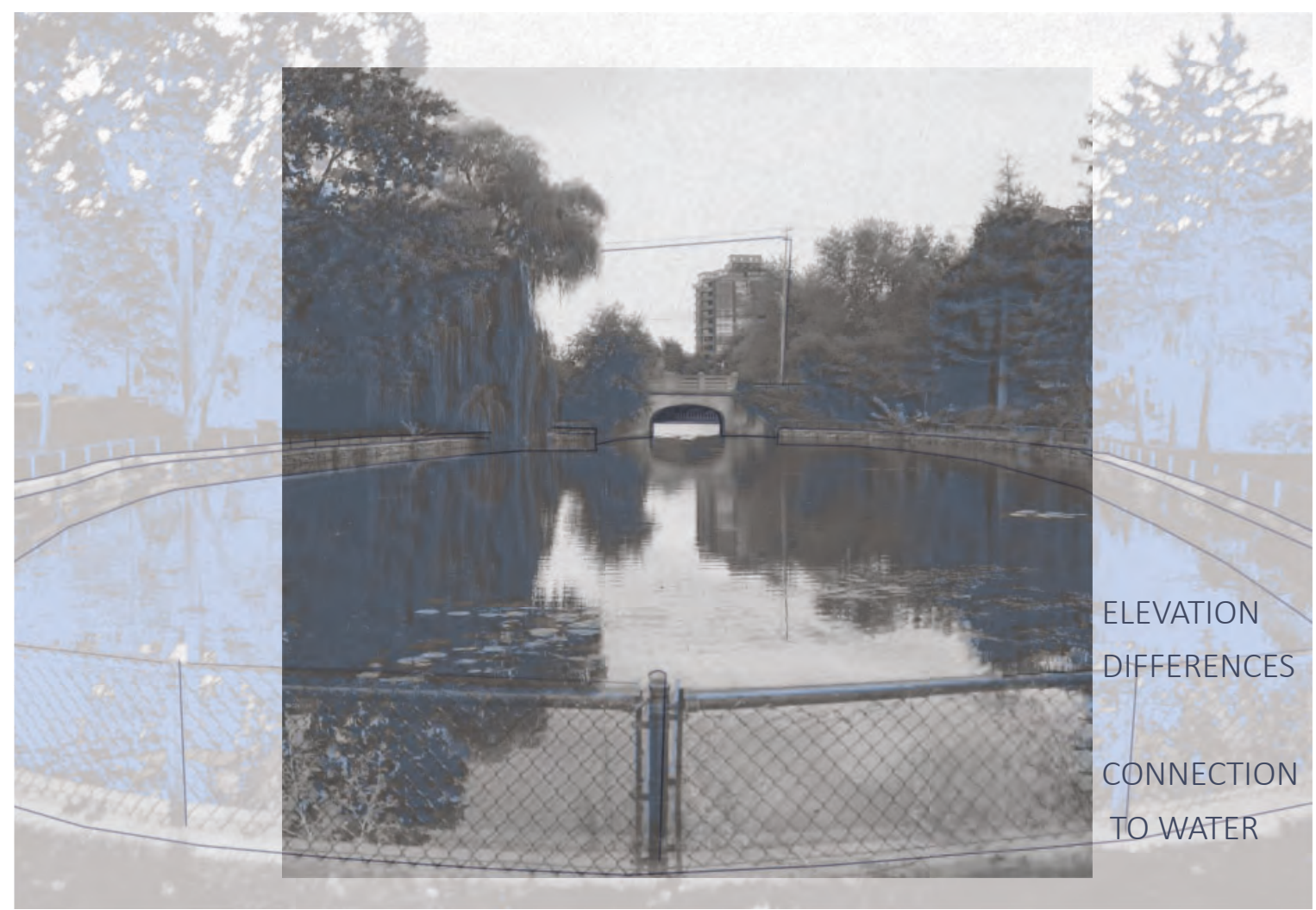

Figure 021 - Blue Space - Photograph

Blue Space is a space with anything to do with water including, water features, ponds, lakes, fountains, rivers, and water ways.

Located within a residential neighborhood, this blue space site is in Paterson Creek Park close to Clemow Avenue. The primary constraint of this site is it's separation from the rest of the park by steep inclines next to a bridge on one side, and a road on the other. The park is at a lower elevation than the street, and the creek is lower still. The continuity from one section of the park to another is broken by the road. Even though the road is 


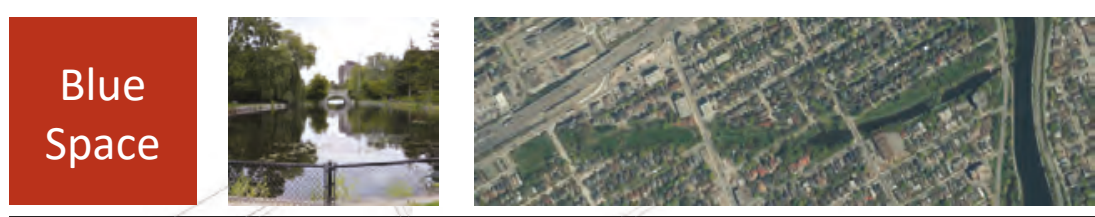

Connectively Challenged - Current Narrative and Site Overview

blocked to through traffic, it still creates

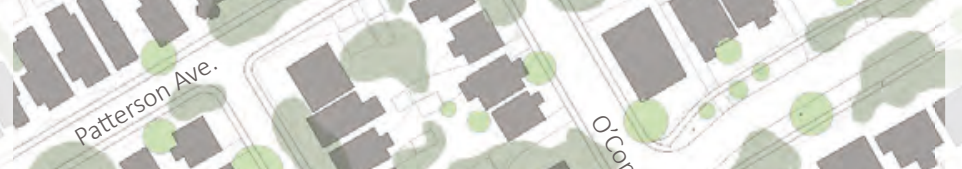
a visual barrier disrupting any continuous flow of visitors from adjacent park lands. Once at the creek there are further obstacles in the form of a low chainlink fence and a vertical wall, which pre-

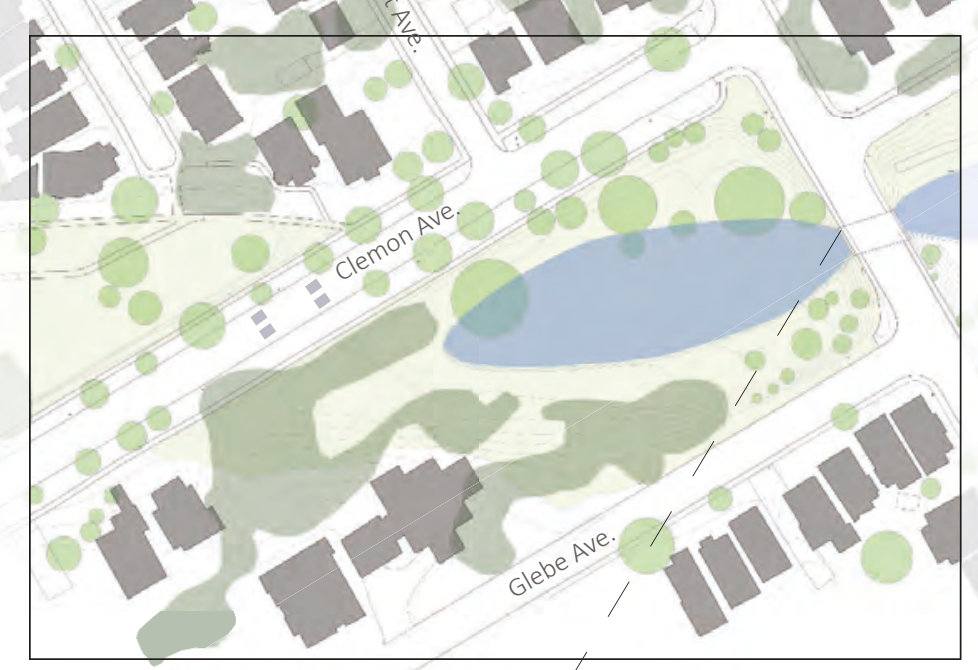
vents direct access to the water. The tranquility at the shore is somewhat impaired by this barrier. One can see but not touch. The water experience could be improved if access was made to be more transparent and inviting.

An intervention to invite visitors from the adjacent park and enhance access to the water will allow the tranquility at Residential Park the water to be better enjoyed by more inhabitants. 


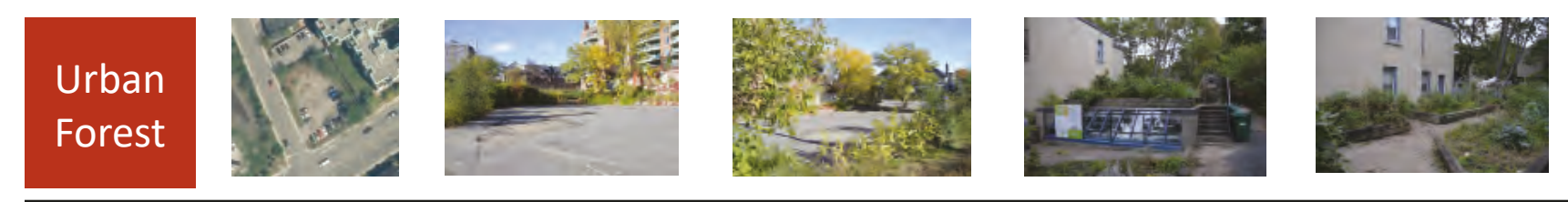

Abandoned_Unused - Current Narrative and Site Overview

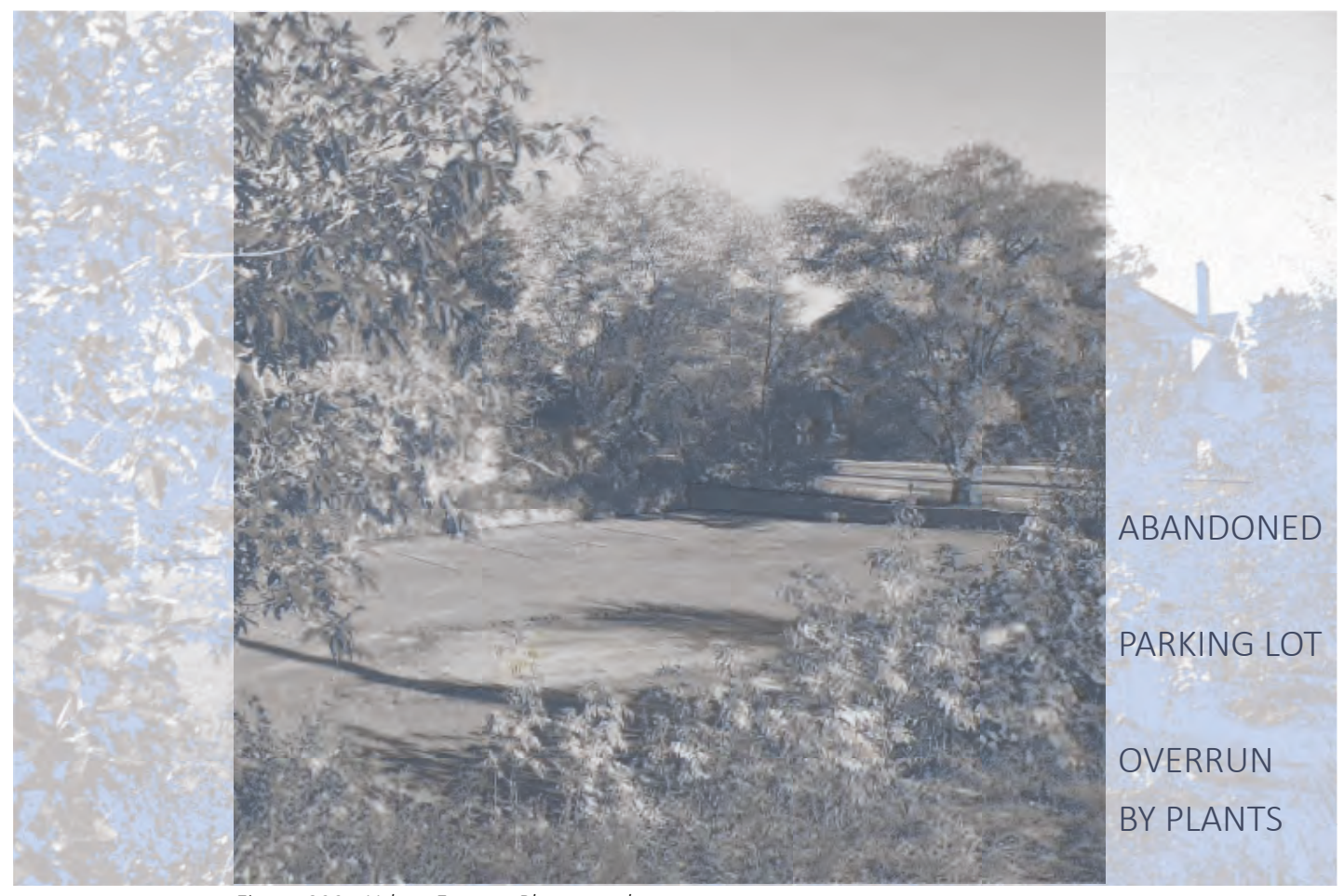

Figure 023 - Urban Forest - Photograph

Urban Forest is a place for trees or other vegetation in an urban environment. Possible locations include roofs, parks, and brown fields.

Upon approaching this site one sees a gradual transition. It was a parking lot, but long abandoned, is in the process of being over-grown with vegetation. It is not functional as a park due to the cracked pavement and not fully functional as a parking lot due to the many over-hanging trees and shrubs. The site is constrained by its current state of transition and will attract and benefit the local residents if it is turned into a green area. 


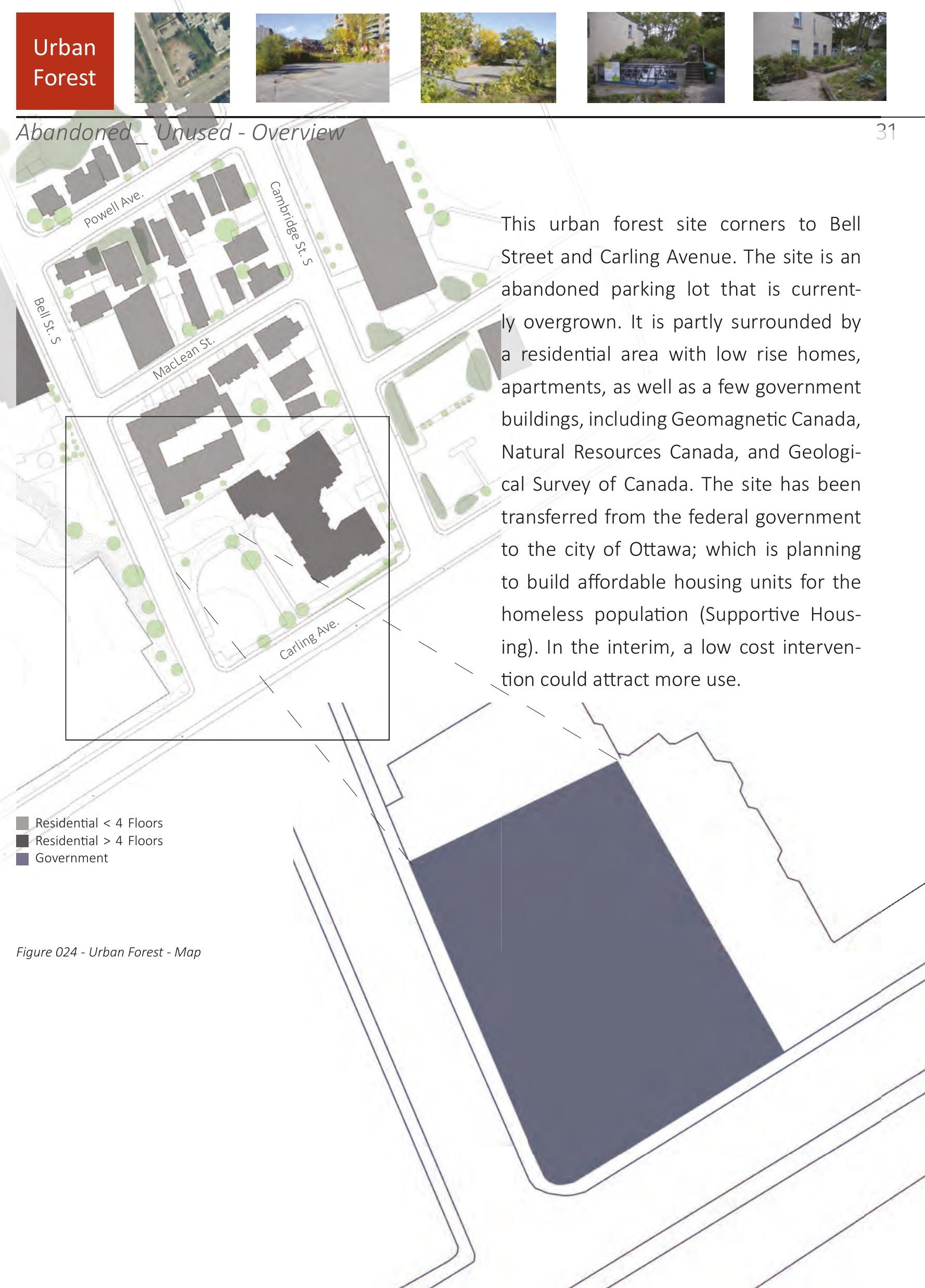




\section{3- Proposed Narratives and Interventions}

The six spaces explored each have a narrative or story shaped by the characteristics of the site. The prior chapter categorized and assessed the spatial conditions of each site thereby generating a starting narrative for each.

This chapter proposes a new narrative and offers spatial strategies and interventions. Applying interventions to each site will force a transformation and result in the realization of a new enhanced narrative.

What does it "mean to form and transform the places we inhabit? Is transformation something that just happens in the collective process of daily lives? Where do we set out to transform urban environments with active intent?" 14

The continued exploration of 'the space between' will emphasize actively planned interventions that satisfy the key objectives of increased inhabitation and an ability to provide for multiple uses. 


\section{Types of Devices}

spatial Conditions

Devices may be applied to sites to modify their spatial conditions. One or more of following devices will be applied to each of the six transformative public spaces in the form of spatial strategies and interventions in order to enhance the space between by increasing the habitation potential of each site.

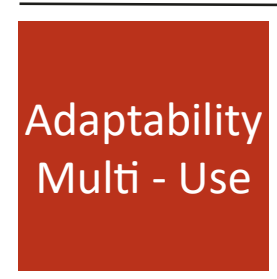

Adaptability is the built-in ability to adapt and adjust to change by meeting different uses, allowing various spatial and functional configurations, and updating technologies without requiring significant disruption of the building or site, the ongoing activities within, and the environment. Multi-Use refers to the ability of a space to continually change to satisfy the needs of those activities and events required by the inhabitants at a particular time.

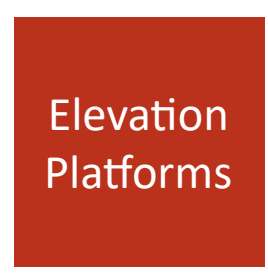

Elevations or Platforms are devices that transform a space in a way as to change people's perspective of the area. Applying this device will help mitigate the impact on a site from the presence of awkward terrain or differences in height within the site and the surrounding area.

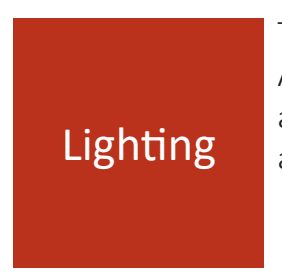

There are different types of Lighting, including Natural, Electrical, and Mood. Altering the brightness can make the difference between a pleasant space and a dreary space. The difference in lighting can deeply affect the quality of an area and thereby attract or deter habitation.

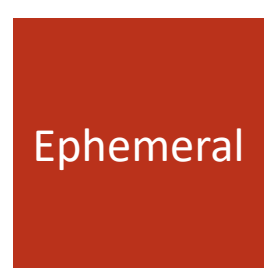

Structures or features which are Ephemeral, are temporary, lasting for a short period of time. Such structures include Pop - Ups: something that is easy to assemble and disassemble that changes a space [providing a welcoming surprise]; Open Street: use of a whole road for some event without live traffic; or an Interim Public Plaza which will dress up a paved area quickly and inexpensively.

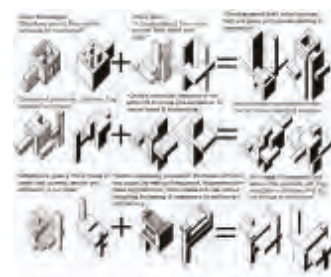

Figure 025 - Adaptability

\section{- Image}

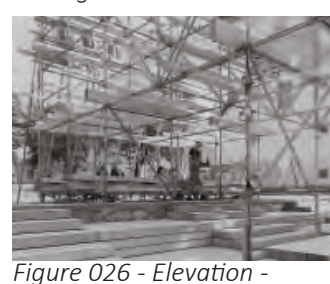

Image
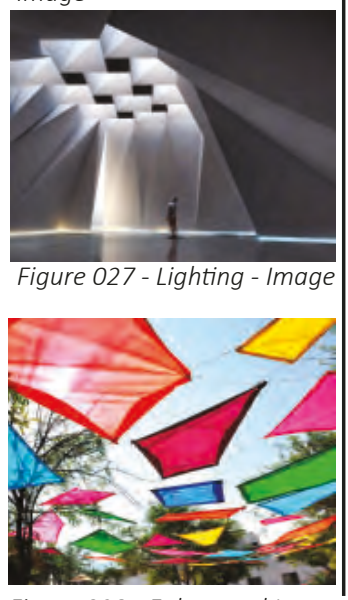

Figure 028 - Ephemeral Image 


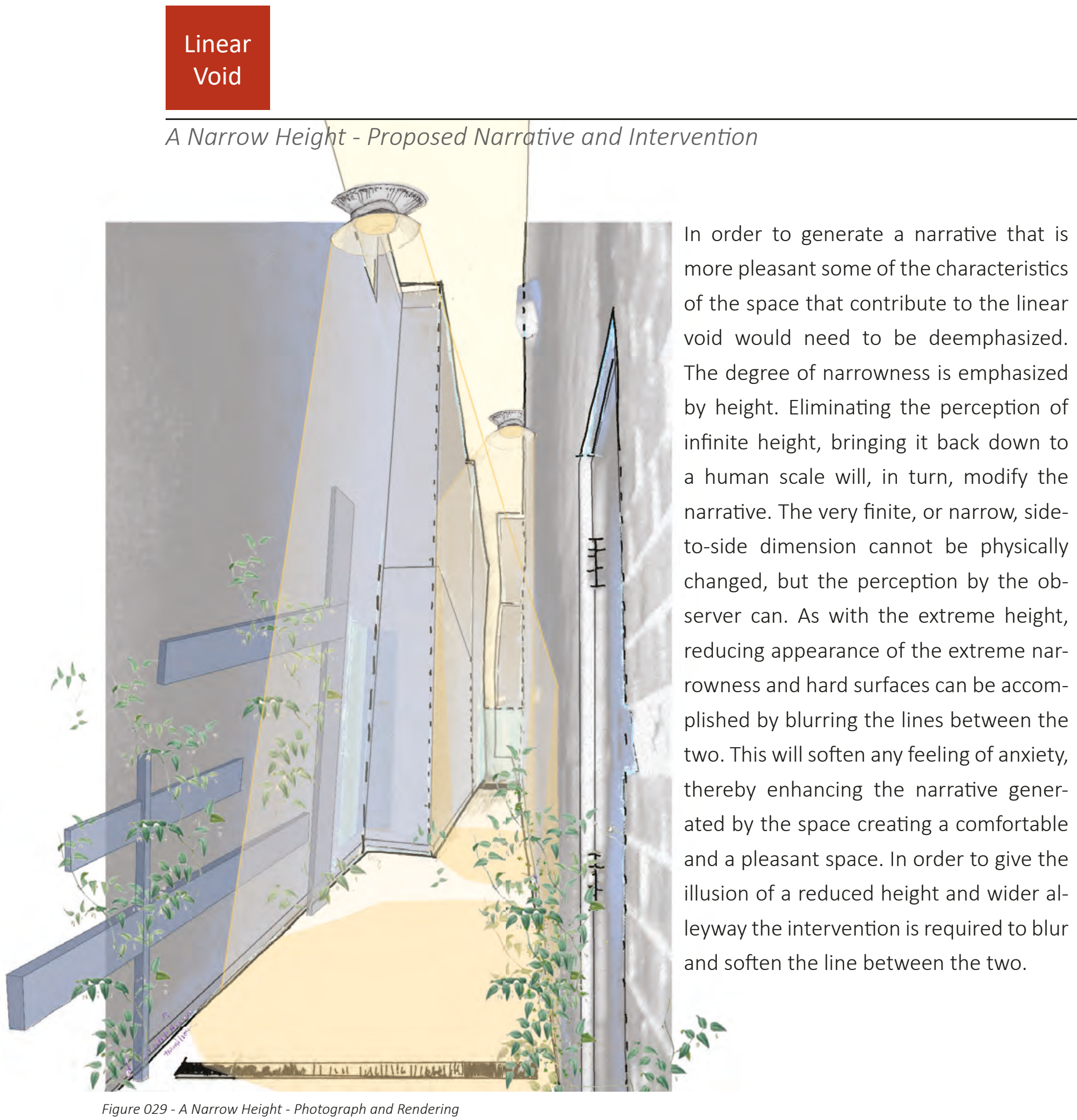




\section{Linear}

Void

A Narrow Height - Proposed Narrative and Intervention

The interpretation of a linear void tends to be one of the most extreme examples of 'the space between' when measured by the contrasts within the space. The void can be characterized as negative space and the adjacent areas as positive space. There is no balance between the two. More balance can be created by deemphasizing the negative space by adding some positive elements, essentially softening the line between the two. The increased sense of balance will tend to modify the narrative to portray a more friendly and pleasant environment for the observer.

This concept can be applied to transform the linear void of the alley at the Preston and Gladstone site. Since the alley and narrow space between the walls represents the negative space and the walls represent positive space, more balance can be created by de-emphasizing the long, narrow, and tall alley by adding positive elements into the void. This will blur and soften the line between the void of the narrow alley and the surrounding walls.

To accomplish this intervention a lighting strategy, in the Figure 030 - Linear Void: Negative and Positive Space - Photograph and Rendering form of additional focused lighting, will be applied to the space. In addition to this device, the use of natural elements such as wood and vegetation will be applied to some of the walls in order to soften them and emphasize 


\section{Linear}

Void

A Narrow Height - Proposed Narrative and Intervention

the human scale. Adding sparsely spaced horizontal and a few vertical wooden panels along with vegetation will not only accomplish the objective of softening the lines, and surfaces, they will also act as accents for the space. Through the combination of these two devices, lighting and use of material to fill in some of the alley/void, an additional dynamic effect of softening the line between the two will occur through the variations in light intensity and shadow. Both combined will add depth to the narrow dimension of the alley .

Creating lenses above the alley will focus light into select spaces below during the day creating a rhythmic pattern of light with varied brightness along the length of the alley as well as up and down the height of the walls. The lenses vary in size and intensity to bring more light into some areas and less into others. In the evening, supplementary electrical lighting within the lenses will provide the same effect.

The light strikes the textured material on the walls, while partly filling the void, creating pools of light and shadow NATURAL LIGHT GOING
INTO THE SPACE in and around the wood paneled walls and the integrated vegetation. 


\section{Linear}

Void

A Narrow Height - Proposed Narrative and Intervention

This intervention will give the illusion that the space is not as narrow as it is. Narrow alleyways and other linear voids have a purpose, even if not obvious to the observer. The purpose may simply be to provide some type of access to the business, an alternate form of egress, or provide access to service utilities or to accept back-room deliveries of food or supplies. This transformative intervention preserves the original purpose of the alley, while transforming it into much more - an area the business owners need not hide from their patrons. Perhaps a boutique restaurant would even prefer to use the alley as an alternative entrance to enhance the experience for their customers. 


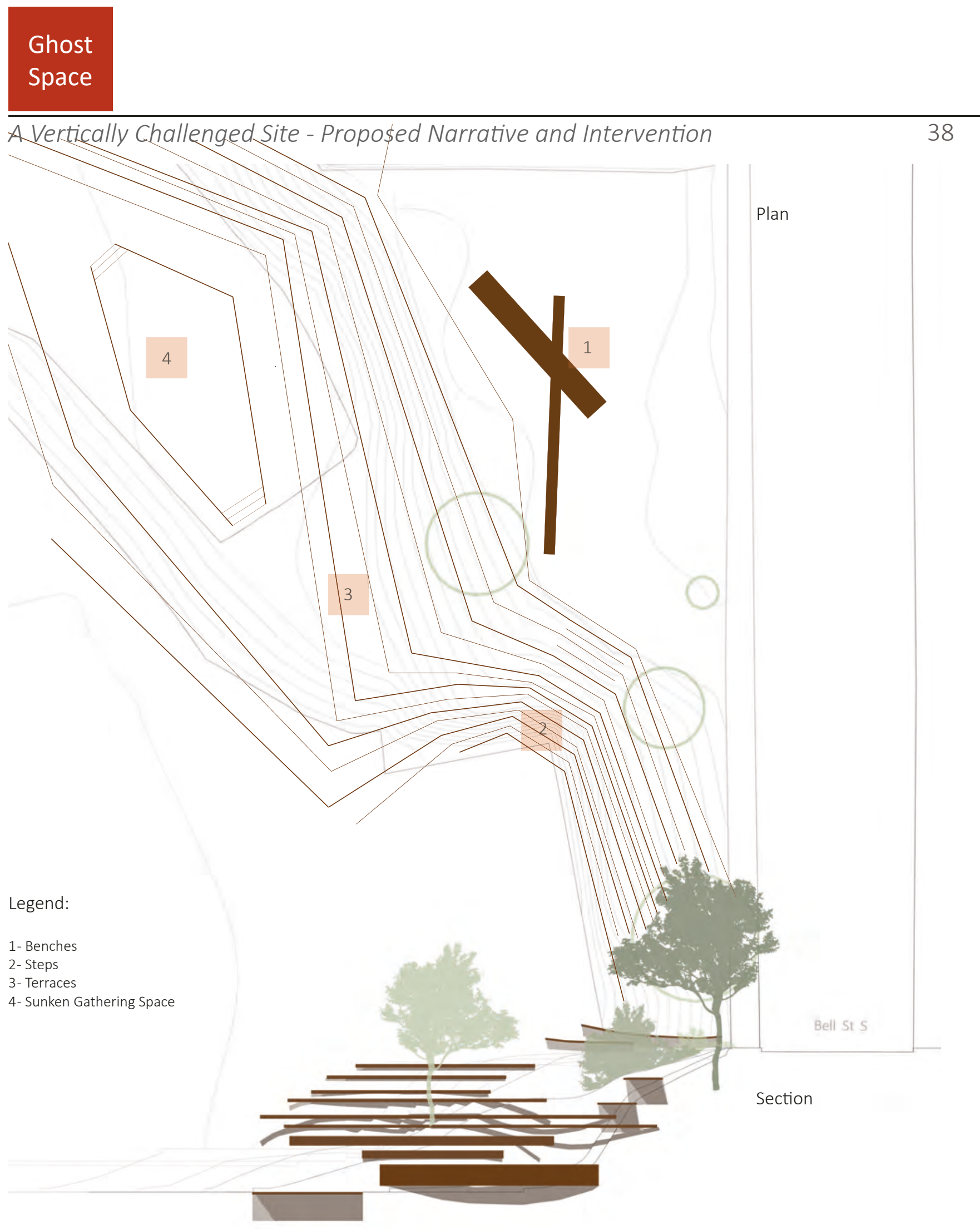

Figure 032 - Map, and Section of the design of the Ghost Space 
Post intervention, the space is no longer a ghost. It is now visible and accessible from Bell Street. Further it is inviting, with asymmetrical benches placed at a distinctive angle, on the same elevation as the street at the top of the hill. The benches act as a functional form of art to attract residents from the street. From the benches people view the multiple terraces descending to the lower elevation and enjoy the landscape. The space has been transformed into a gathering place for the nearby residents and government workers alike. The ghost space is now a true space between the residential area and government facilities. This transitional space has become a destination, promoting interaction and connectivity on the site, linking the street to the government buildings below, and may now be inhabited throughout the day.

To satisfy this narrative of transforming a ghost space into a connecting space and gathering place an intervention is required to address the primary constraint of differences in elevation. 
As implied by the name ghost space, this transformative site is in a state of dislocation, abandoned, and unable to interact with local residents. Without the possibility of interaction, this space becomes an obstacle. The elevation platform device proposed in the intervention will take the form of terraces transforming the significant change in elevation on this site into smaller and more manageable levels. The terraces are at a human scale allowing interaction with residents and thereby providing a connection to the adjoining spaces.

The functional terraces not only satisfy the proposed narrative, they also create more level usable spaces less hazardous to the public, thus eliminating the need for fencing around the site. Large benches, designed to be visually appealing and functional, are strategically positioned at the uppermost level near the street, an invitation drawing people in to occupy the site. Once there, the terraces are in view and provide additional gathering places and viewing locations for impromptu events in the parking lot of the adjoining government facility, completing the transformation of this dislocated ghost space into a connected inhabited destination. 
Seasonal

Space

Cut Through - Proposed Narrative and Intervention

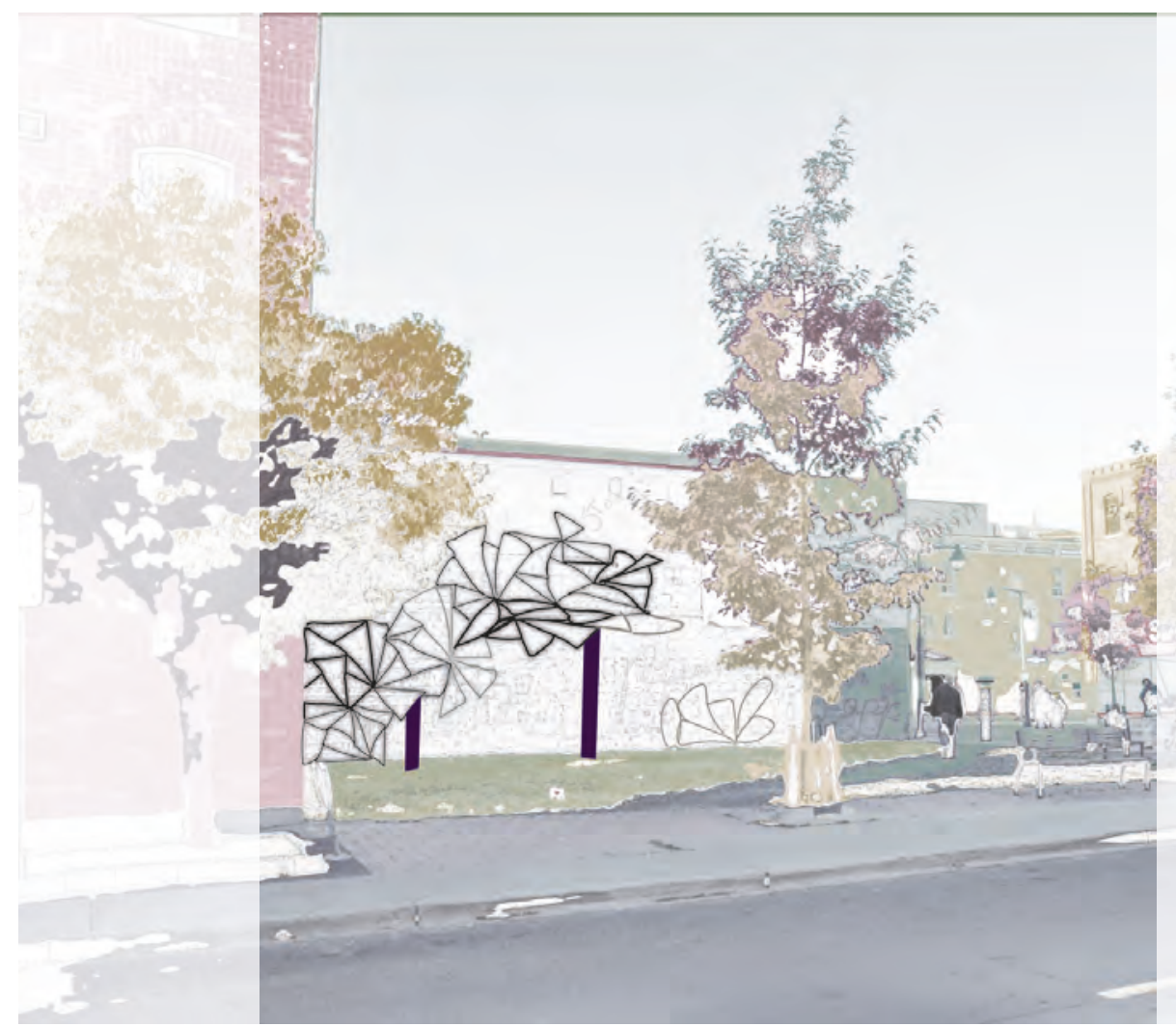

Figure 033 - Seasonal Space - Photograph and Rendering
This transformed space is no longer semi-abandoned and lethargic. It now satisfies more than the single function as a short cut, cutting diagonally from one street to another.

Inhabitable zones attract more visitors that may choose to stay for a longer period of time. Smart-benches provide charging stations for electronic devices as well as ambient lighting on dark evenings as dwellers enjoy art sculptures and decorative murals. For some the site still provides a means to quicken their travel time to some other destination by taking the diagonal short cut. Now the journey is made more pleasurable than before. For others it has become a place to enjoy spending time rather than trying to save time.

An intervention is required to address the primary constraint of not being an inviting place to spend time. The proposed solution transforms a seasonal transitory space into a space that could be used regularly and provide enjoyment to those using the site. 


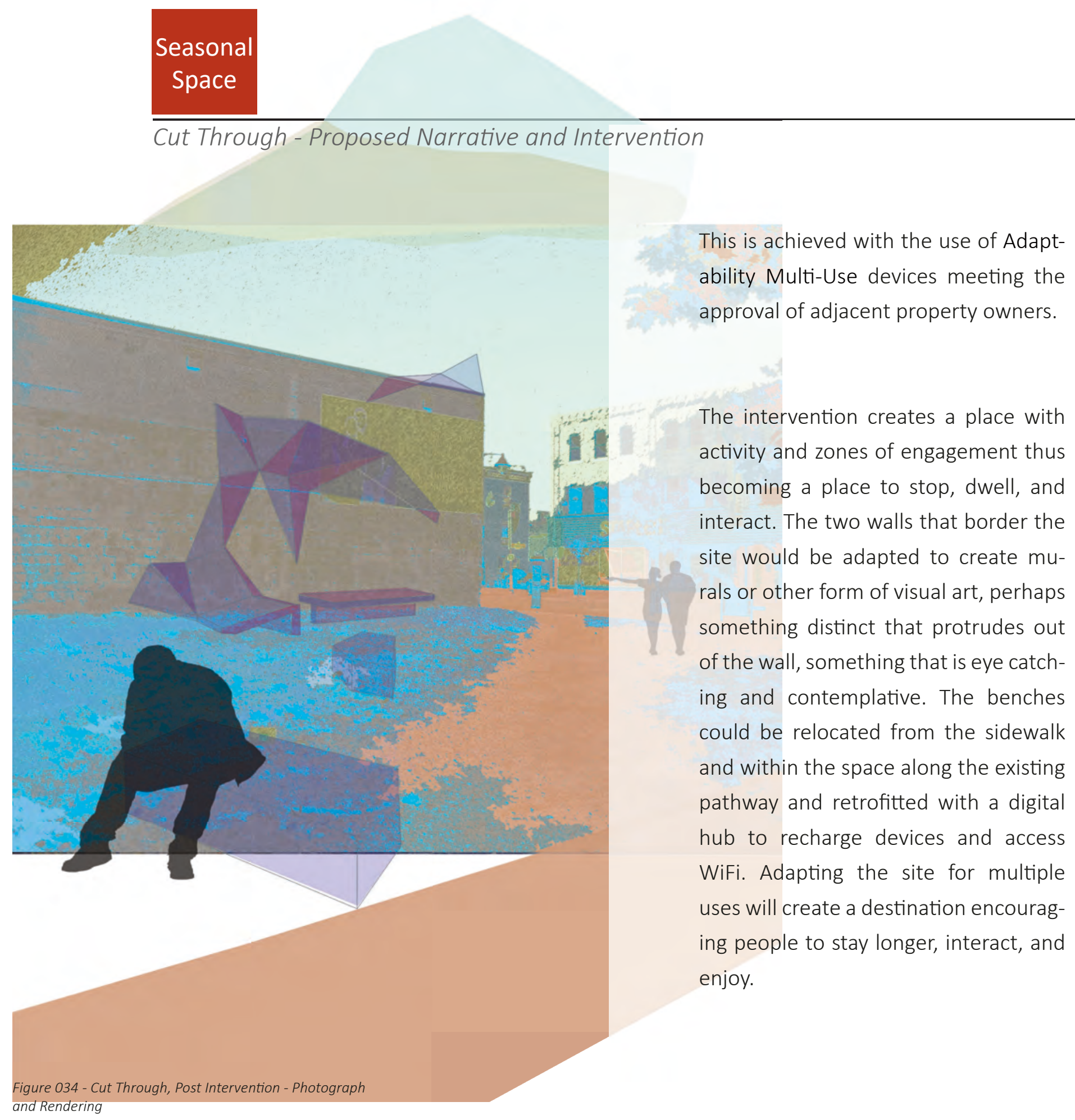


Residual

Space

Dead End - Proposed Narrative and Intervention

A revised residual space is no longer under-utilized. It now accommodates more requirements and situations. It is a small, intimate, clean space that is capable of hosting former activities as well as a new set of diverse functions. There are still concealed facilities to address garbage bins and other storage requirements of adjacent businesses. Added are permanent areas for vendors as well as spaces for patios, food trucks and pop-up structures. The site is now able to attract and provide services to many more inhabitants and with a greater variety of functions.

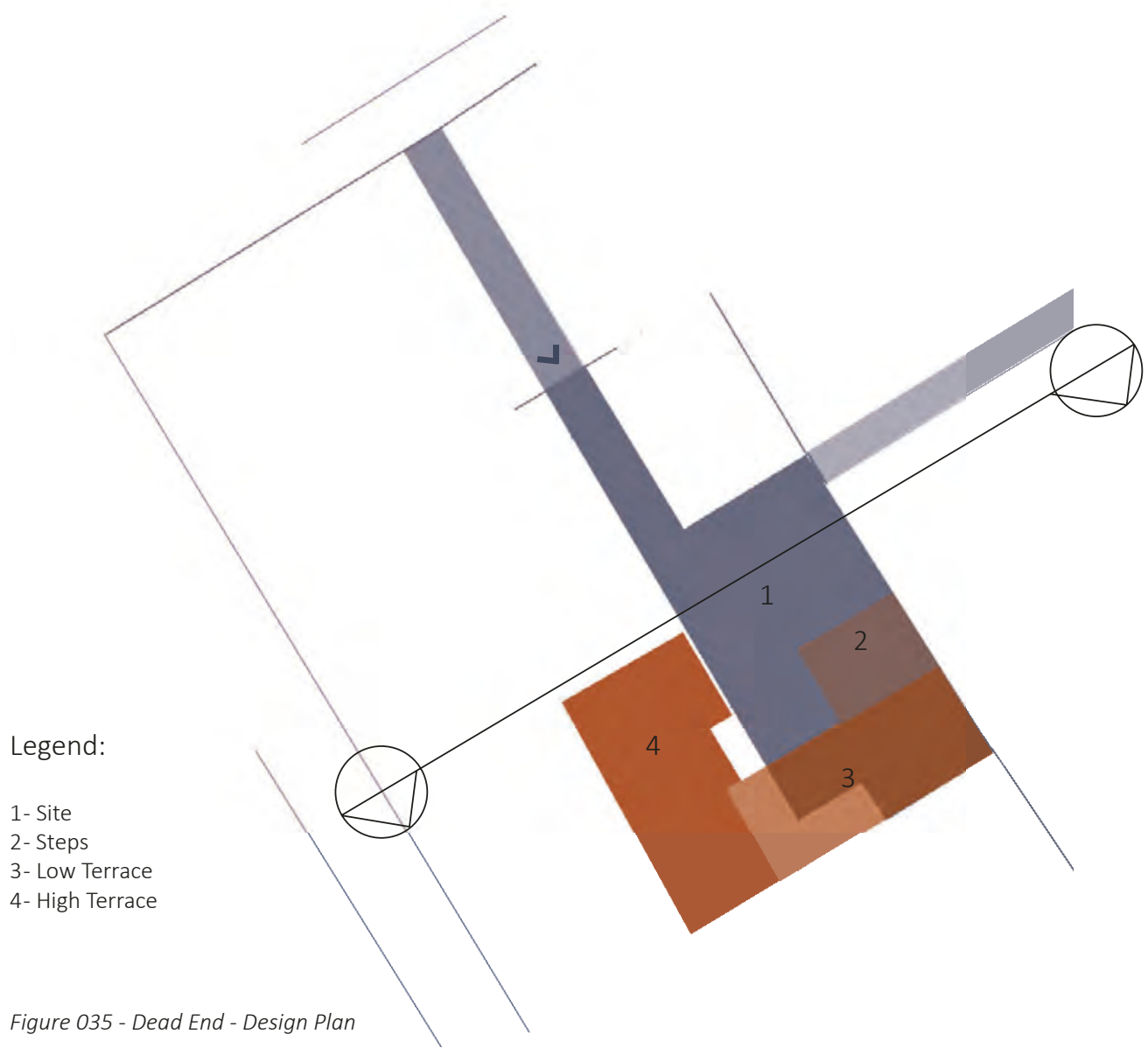




\section{Residual}

Space

Dead End - Proposed Narrative and Intervention

To satisfy the proposed narrative to transform a residual under-utilized space into a vibrant space that could be used regularly for a diverse set of activities requires a multi-faceted approach. The intervention must consider that this site is an open, yet private space. Therefore current business needs must still be satisfied while the transition attracts more of the public to the shared space. Increased habitation will further benefit the businesses by drawing in more potential customers.

To transform this site into one that increases the level of utilization several devices were applied. Adaptability is used to ensure no interruption to business activities or current use of the space during the transformation process. Multi-Use will be applied to ensure current uses of the space will persist while new uses for the venue can

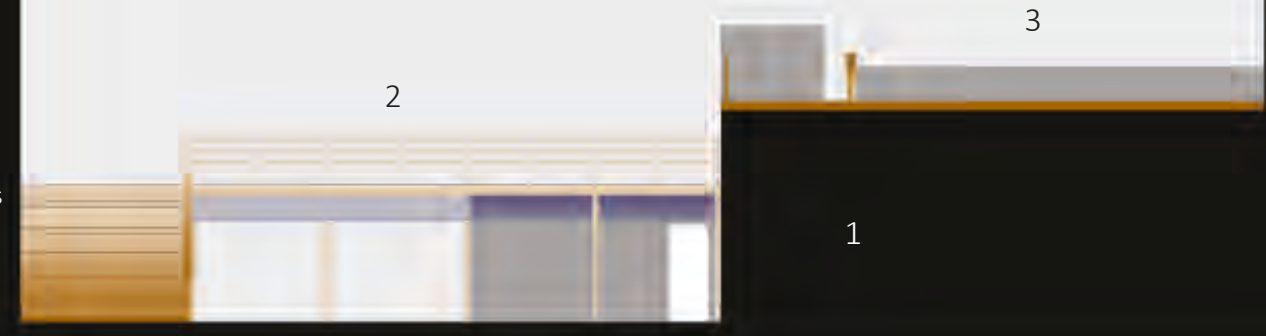


Residual

Space

Dead End - Proposed Narrative and Intervention

be supported. These range from intimate gatherings to art exhibits and celebrations. With the support of business and property owners a mural can be placed at the entrance to catch the eye of passersby, attracting attention to the space.

An elevated platform device in the form of a terraced courtyard will connect the first and second levels of the area and provide a new perspective onto the space below. The view from the terrace onto the former full-time parking lot, now a manicured and cleaned up courtyard, will provide space for various ephemeral pop-ups and organized events.

Directly under the terraces, storage for the existing shops are interspersed with spaces for new stalls used by vendors or exhibitors.

This space between buildings can now be fully utilized as an intimate focal point inhabited by local residents and visitors alike. 


\section{Blue}

Space

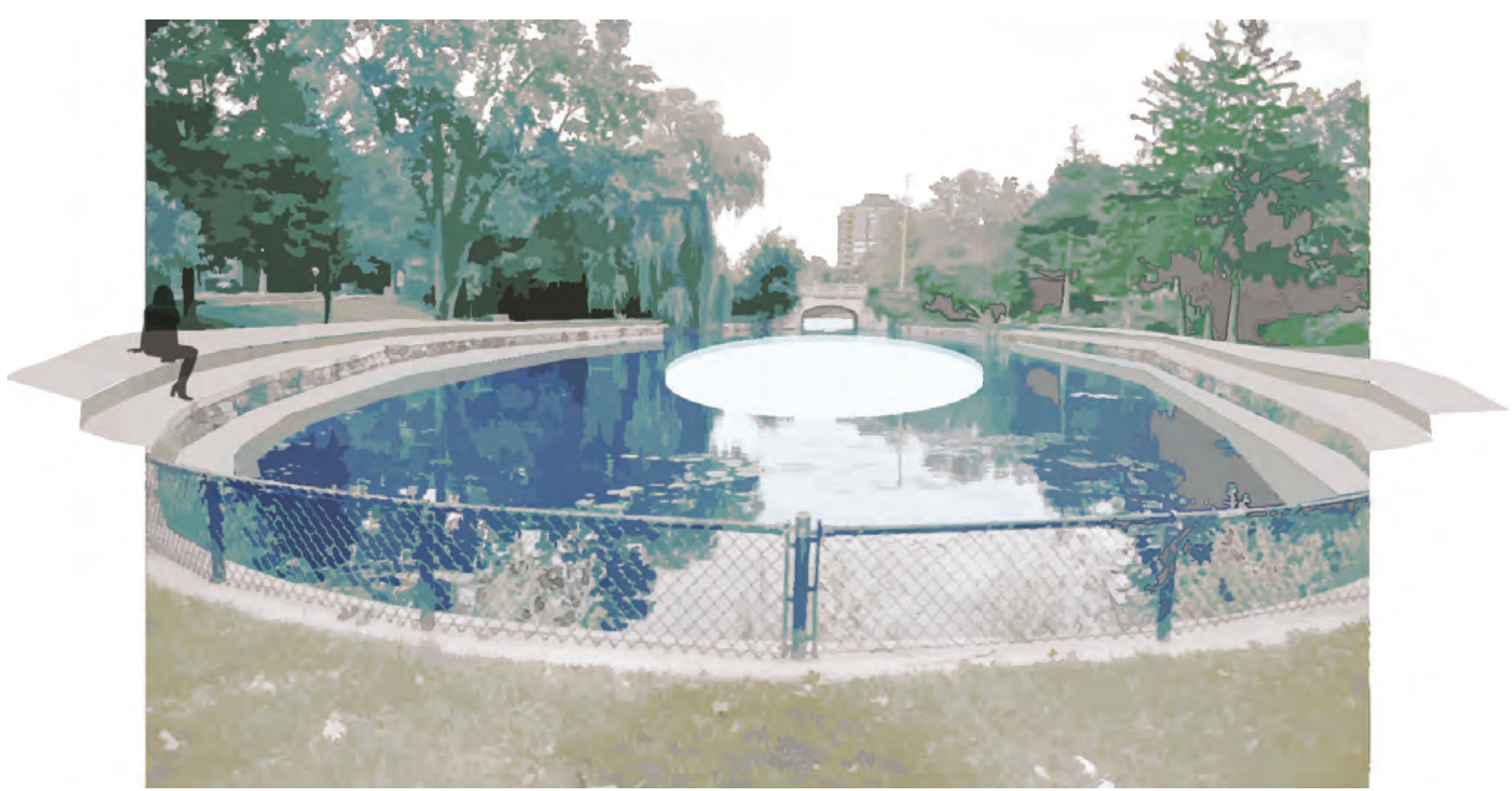

Figure 037 - Blue Space - Photograph and Rendering

With a few modest interventions, the water at the centre of the site is now inviting and open to approach. The public can interact with the water and get closer to its surface by walking along or sitting on the steps leading to the water's edge. With a fence no longer encircling the whole perimeter, there is a greater sense of connec-

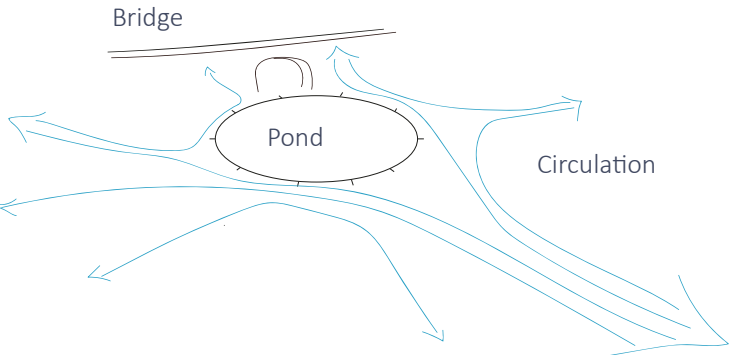
tivity with the landscape.

Not only are visitors able to take in the tranquil setting and relax, they can enjoy a performance taking place on the proposed floating dock near the bridge. From their vantage point, either on the steps at the water's edge or from the pick-nick area on the hill leading down to the water, dwellers will have a clear unobstructed view of the staged events. 


\section{Blue}

Space

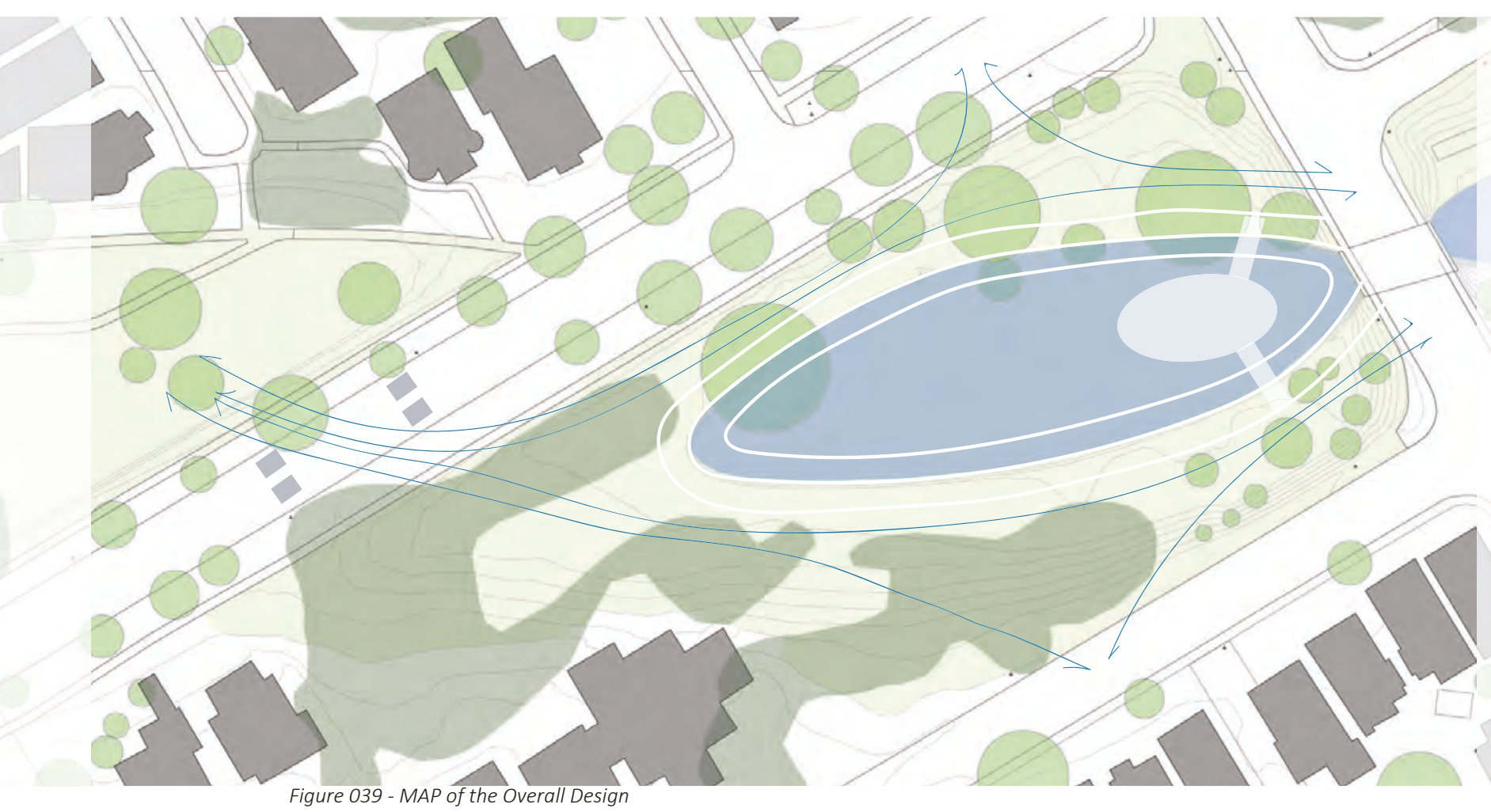

The walk from the adjacent park to the creek is now unencumbered, hence there is no need to leave the path as it now bisects the road instead of the other way around. A visitor no longer has to cross the road, and can simply stay on the path. There is now a contiguous link from one section of the park to the next and to the water.

To realize the proposed narrative of transforming this blue space to be more connected with the adjacent park, an intervention is required.

The intervention respects the existing roadway over the bridge since traffic flow must be maintained. It will, how- 


\section{Blue}

Space

Connectively Challenged - Proposed Narrative and Intervention

ever, enhance connectivity in other ways to make this public space feel open and welcoming and less like a private and restrictive space.

In an effort to make the entrance to the space an extension of the adjacent park the circulation of he pathway has been altered. Instead of ending the path at the blocked road and restarting on the other side of the road, the path now continues over the road, without changing form and without needing to step down and up onto a curb. As a result, the path becomes continuous and the road remains blocked by the existing concrete platers. To maintain traffic flow, the other road over the bridge bisecting the site, will not be blocked, however a path will

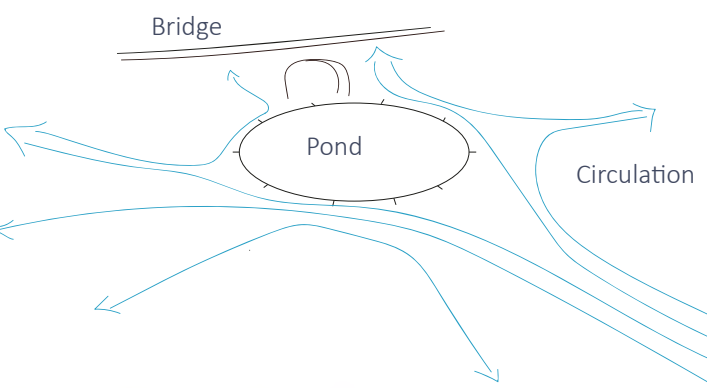

Figure 040 - Sketch of the New Circulation of the Space

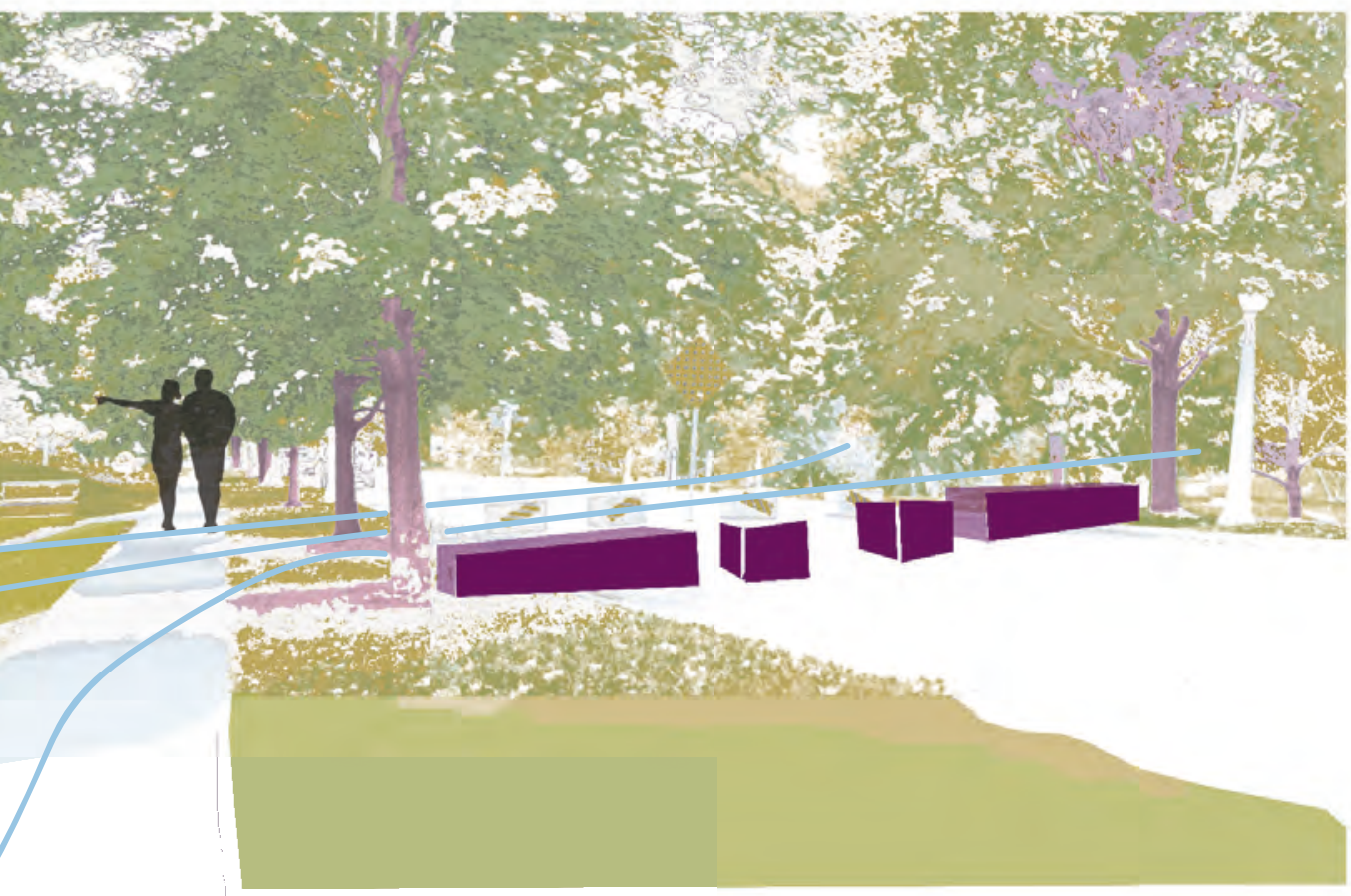

Figure 041 - Continuous Path - Photograph and Rendering 


\section{Blue}

Space

Connectively Challenged - Proposed Narrative and Intervention

still cross on top of the road in the form of a cross-walk, or if pedestrian traffic warrants it, a metered light.

The theme of connection throughout the space continues at the water's edge where an elevated platform device is applied in the form of wide terraced steps leading down to the water's surface. This softens the space and eliminates the barrier created by the former chain-link fence and vertical wall. If water levels rise, only the lower steps will be covered and can be restored once levels recede. There will be no impact to the remaining step terraces.

A Multi-Use device is applied in the form of a floating stage, located in the water near the bridge. This feature enables multi-use capabilities for the public space. Visitors are able to take in the tranquil setting and relax, while at other times they may take in a performance or play. In effect, the lake and surrounding hills transform into a amphitheater.

The intervention will provide value to the neighboring residents and visitors and increase the habitation of this public site.

Not only is connectivity to the water enhanced, there is now continuity between this site and the adjacent parkland. Pathways connect and cross the blocked road to enhance the sense flow from one section of the park to the next. 


\section{Urban}

Forest

Abandoned Unused - Proposed Narrative and Intervention

This urban forest is now transformed to a natural state without many visible reminders of the parking lot it once was. The small forest now provides a calming escape from the surrounding city. Perimeter vegetation with interior benches, trellises, and pathways provide the perfect quiet space for contemplation.

The proposed narrative - encouraging the complete transformation of this site into an accessible and enjoyable urban forest - can be accomplished through minor intervention. Adaptability is provided by the introduction of structures upon which greenery can take hold as it grows.
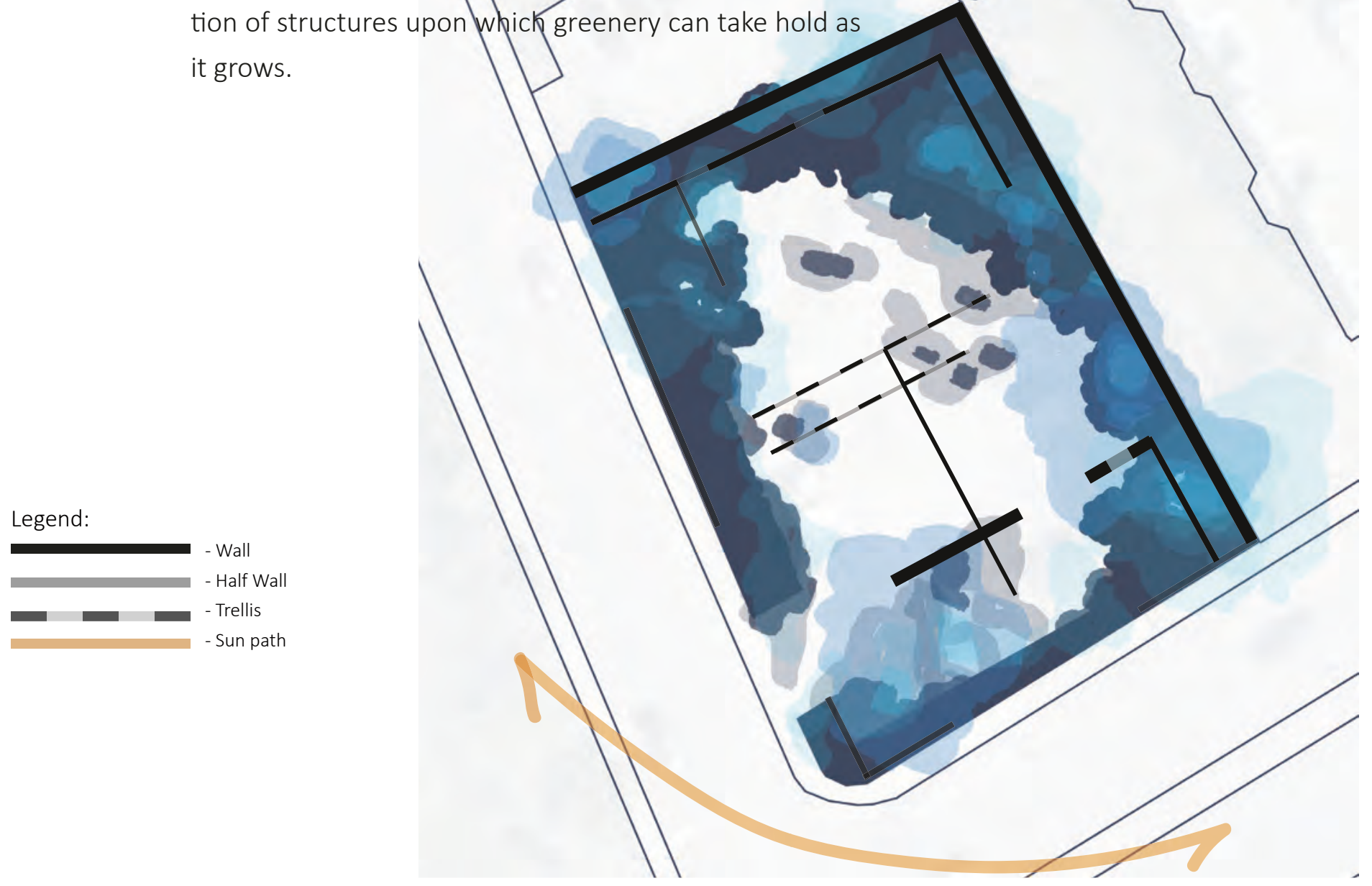
Urban

Forest

Abandoned Unused - Proposed Narrative and Intervention

Such structures will include contemporary wooden trellises and partial interlaced walls. Perimeter vegetation will be encouraged forming a sound barrier between the inner forest and the adjacent busy Carling Avenue. Most of the parking lot pavement will be removed from the site to further encourage plant growth. The inner forest will include pathways from any remaining parking lot pavement and benches for visitors.

This tranquil public space will service the residents of the neighborhood who will inhabit the space at various times and provide a quiet place to escape the city and engage in contemplation or simply relaxation.

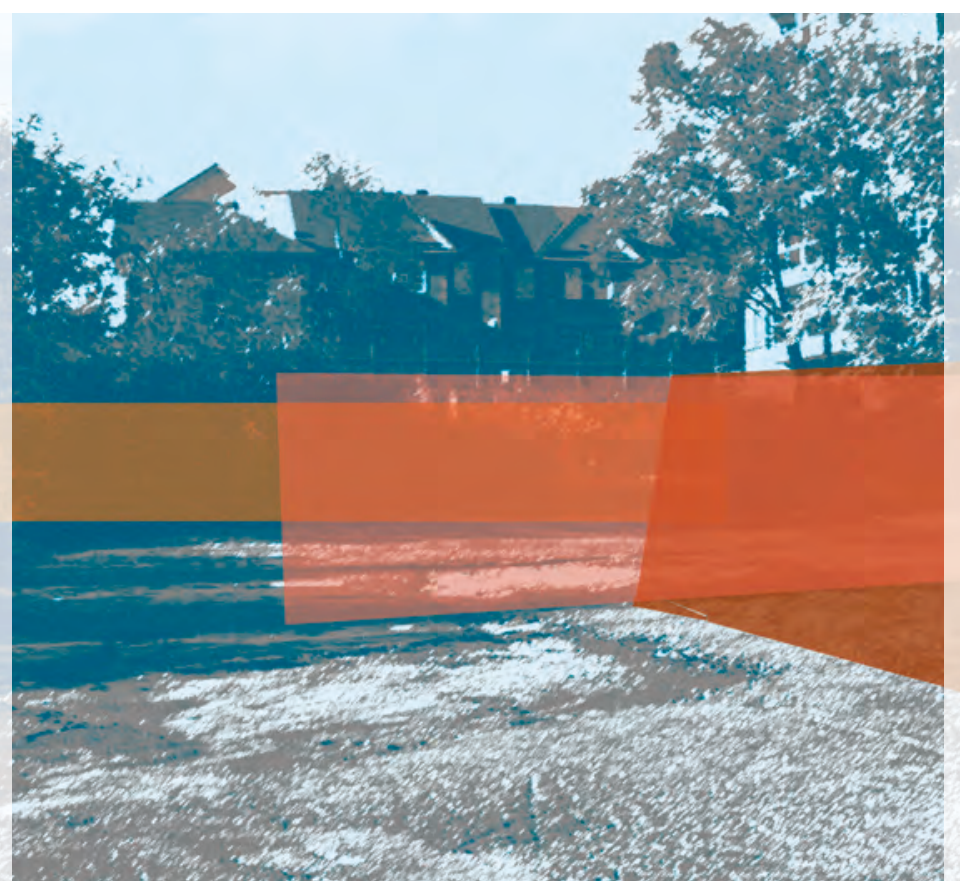

Figure 043 - Urban Forest - Photograph and Rendering 


\section{Project Evolution}

Human needs evolve with time. Space must be fluid to accommodate changes in attitudes and priorities of the surrounding inhabitants. What was once useful space in the past may become obsolete in the present. Conversely, space thought to be of no value in the past and left abandoned, may now have hidden potential. As demonstrated throughout this thesis, transformed space can create experiences that are transformative to the inhabitants. Through the use of well-analyzed and appropriate spatial strategies and interventions, a space in a state of decline can be transformed into a new space with a new narrative that satisfies current human needs. Through the use of devices such as adaptability and multi-functionality in spacial strategies, a space can continue to be relevant and adaptable to future needs as humans and society continue to evolve.

In an effort to demonstrate this principle, the six sites studied were selected to be distinct from each other, with each having a specific spatial condition: linear void, ghost space, seasonal space, residual space, blue space, and urban forest. There are many sites within the city which share the same spatial conditions as the six chosen, their are examples of each scattered throughout the city. The sites chosen best exemplify the spatial conditions to be examined. Alleyways are created by the close proximity of many commercial buildings throughout the city core, tend to be narrow, dark, and have limited ac- 
Postscript

cess. The site that was chosen best exemplifies the characteristics of linear void as previously demonstrated.

Each site was either a publicly held or privately owned space. Those that were privately owned businesses tend to have public access and owners would benefit from an increase in pedestrian traffic. Open access to a space, even if to use a service provided by a business during certain hours, is still considered publicly accessible space, regardless of ownership.

An analysis of each site and the adjacent space is essential to understand the current condition and possible outcomes from interventions. 'The space between' may be difficult to access or simply underutilized and bordering focal spaces with greater purposes. The current narrative for each space was not optimal as it may have been. Each space had constraints that needed to be addressed by the design intervention in an attempt to improve the site. Such constraints included, but were not limited to: extreme narrowness of a site, multiple height and elevation differences within the site, established use as a cut through, dead end, connectivity challenges with adjacent sites, and just abandonment of 'the space between'.

The space between buildings and other focal points or 
nodes must be transversed to get from one place to another. Whether that be from home to work or to a park, enjoyment of the journey can be as memorable as the destination itself. One might contrast walking down a dark, narrow, closed-in alley to a building entrance to walking down a bright alley that is perceived to be wider, softer, comfortable and welcoming. Both experiences may be memorable, but the latter would also be enjoyable. Likewise, a short cut through a featureless space may be transformed to provide an enjoyable excursion through a dynamic area offering services to assist and art to contemplate. Such a space may become a destination rather than a simple nondescript route between places.

As sites are transformed, changes occur in form, appearance, and structure. By extension there is also a change in condition, nature, character, and narrative of the site. The experience is transformative to the inhabitants since the transformation inspires a shift and ongoing change in the inhabitant's viewpoint - they look at spaces in a new way.

As further demonstrated, 'the space between' could also be turned into more of a focal destination by applying various strategies. An oasis sheltered from the city noise by vegetation becomes a destination to contemplate and enjoy nature. Similarly, an existing focal destination can be made more accessible in order to provide a fuller 
and more memorable experience by eliminating barriers. With seamless access throughout a site, visitors can become connected within the site.

The original narratives of all the public spaces explored touched on barriers to access, uninviting, awkward terrain, and underutilization of the space. In contrast the closing narratives referenced increased access, welcoming environment, attraction, gathering spaces, and in some cases multiple usage of the site through ephemeral devices such as pop-ups or performance spaces that are adapted to peoples needs in the city.

How does one measure the success of an intervention to a public space? To measure the success or failure of the outcome, one can not simply examine each component of the interventions.

The impact of alterations will tend to result in both quantitatively measurable improvements such as providing an increase in access to or between spaces and qualitative enhancements such as presenting a greater sense of openness or more pleasant surroundings. The qualitative enhancements may be interpreted positively or negatively, and are subject to the perspective of each person interacting with the space.

Given the choice, people tend to gravitate to places they 
enjoy and provide pleasant memories and experiences. This implies the true measure of success is the increase in the number of inhabitants of the space over any given time. In addition to measuring the quantitative improvements to determine the level of success from interventions on a space, the qualitative enhancements can be measured indirectly by the increase in inhabitation of a space.

The interventions proposed for the public spaces explored in this thesis were the result of an in-depth analysis in order to identify problems, potentials, and positive qualities. Problems become challenges that can be overcome by applying relevant design solutions, in part, through realizing the potential of the site and emphasizing the positive qualities. Each site is distinct and requires a customized approach in order to better guarantee its success.

Through a customized approach, the interventions not only better the quantitative measures of success, the outcome will expect to attract many new inhabitants through qualitative improvements and thereby be an unqualified success. 
The customized approach may also be used to form an alternate transformation by introducing a key design element from different situations. The same key design elements can be used to transform any number of sites. Consider the seasonal space site represented by the cut through at Bank street and the Blue Space Site represented by the connectively challenged site at Patterson Creek Park. A blue space element, such as a fountain, could be introduced into the other site to create a hybrid seasonal-blue space. Adaptive multi-use devices

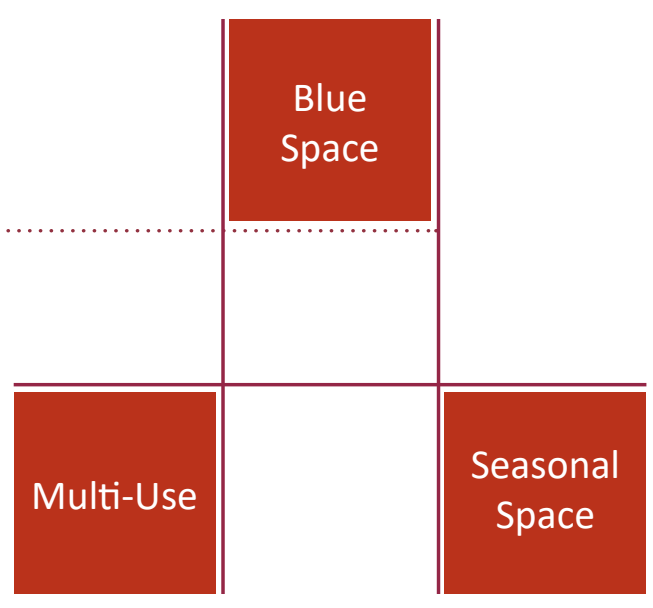

Figure 044 - Combination of Design Elements that forms a new possible situation from the blue space could also be introduced, such as a small stage. This alternate intervention and resulting transformation of the cut-through site will satisfy the proposed narrative - a destination encouraging people to stay longer, interact, and enjoy 'the spaces between'. Through the use of key design elements, transformation scenarios can be created through improvisation. The results change our experiences of the design elements and events occurring within the site, influencing our perception of temporality.

The design strategy is in response to how people use the site and its success can be measured from the observation of their reaction. There is more than one path to success and the path may not only result in transformed spaces, but also result in an ongoing transformative experience for the inhabitants. 


\section{Appendix}

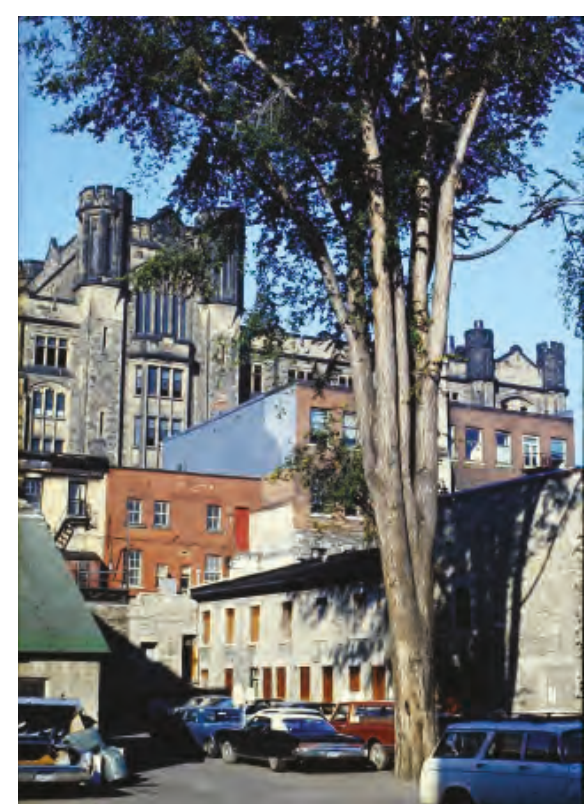

Figure 045 - Photo 1979

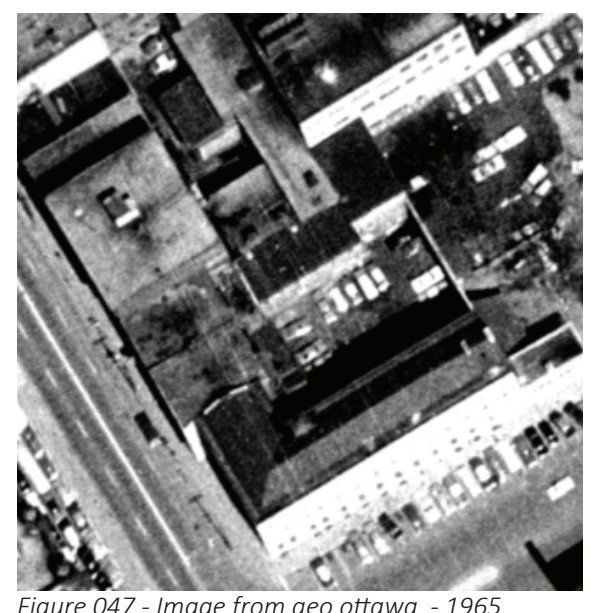

Figure 047 - Image from geo ottawa - 1965

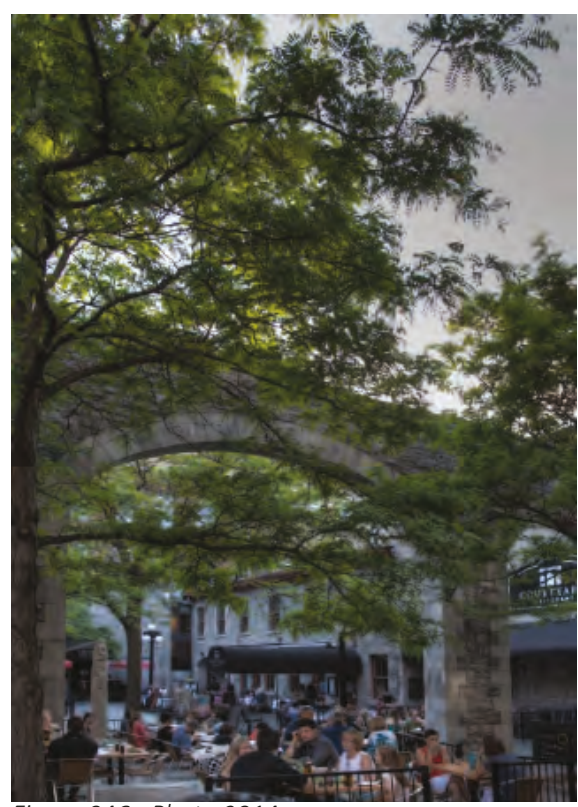

Figure 046 - Photo 2014

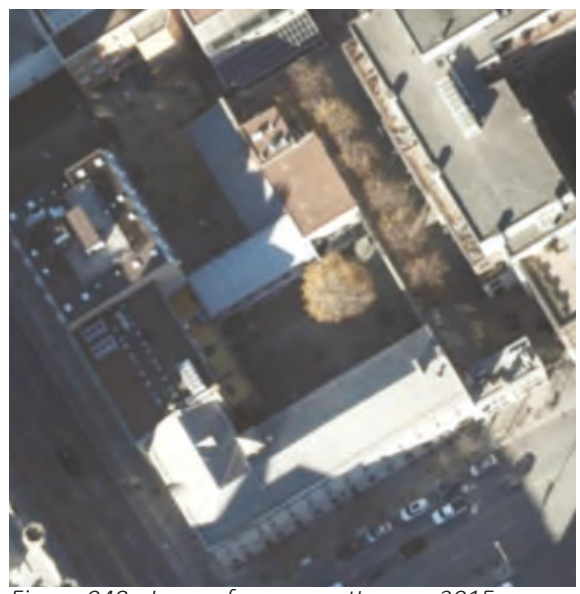

Figure 048 - Image from geo ottawa - 2015
Then and Now - Creating a Space to Gather

\section{Courtyard Clarendon Lane}

Here is a site behind the buildings between the streets of Rue George St. and Rue York St. That Intersects with Prom. Sussex Dr.

This site is no longer underutilized. It was transformed from a parking lot to a vibrant gathering place where people can stroll through or spend time sitting at a table, watching the crowds. The courtyard is also an intimate and secluded space open and used by the public and businesses alike. 


\section{Appendix}

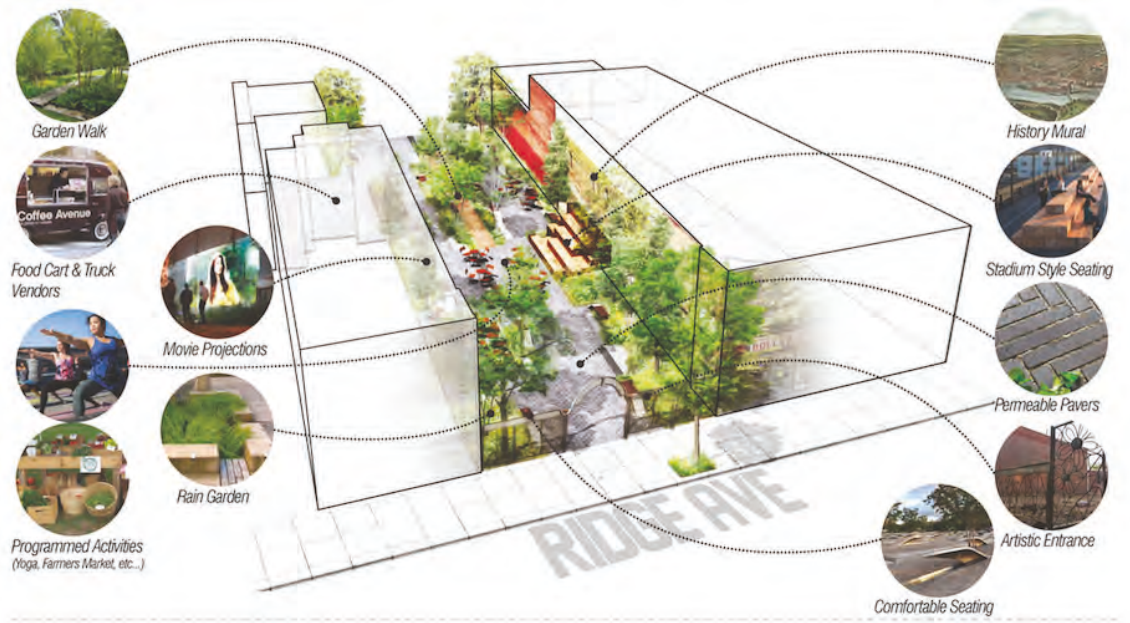

Figure 049 - Park Design

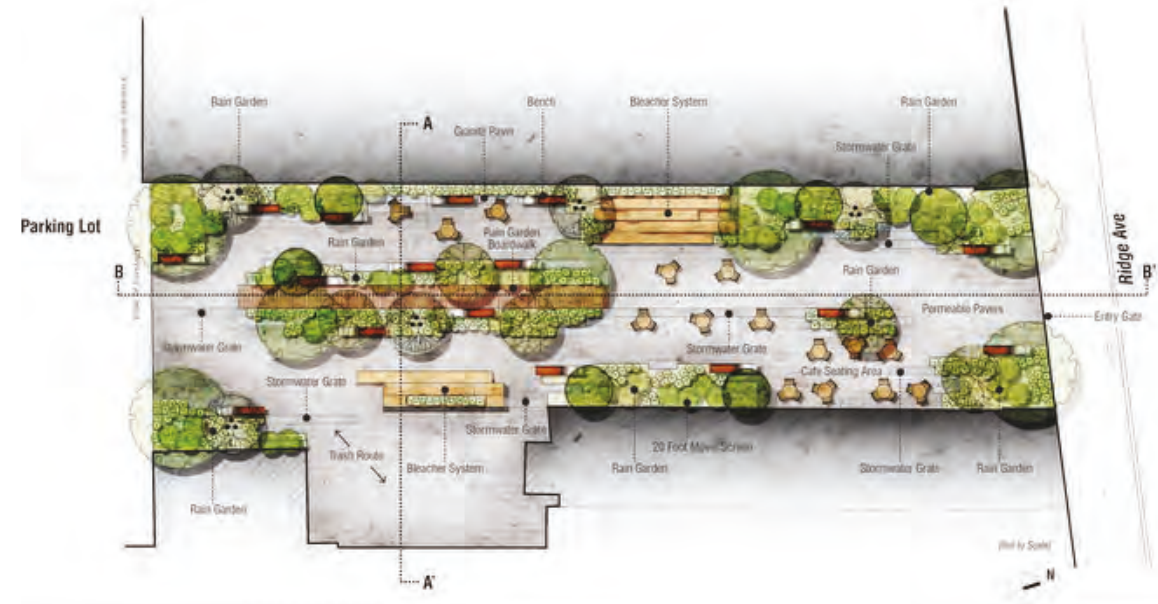

Figure 050 - Park Design
Ridge Ave - Pocket Park

Philadelphia

Creating a public flex-space.

The vision for the park was to transform a once vacant unusable asphalt lot in the heart of Ridge Avenue into a sustainable, green flex space that can be an asset to the city. Adding greenery and other features to create a usable area in the community.

Plans shaped by the community envision a rain garden boardwalk, food carts and truck vendors at the site. Conceptual designs for the pocket park were developed by Groundswell Design Group. 


\section{Appendix}

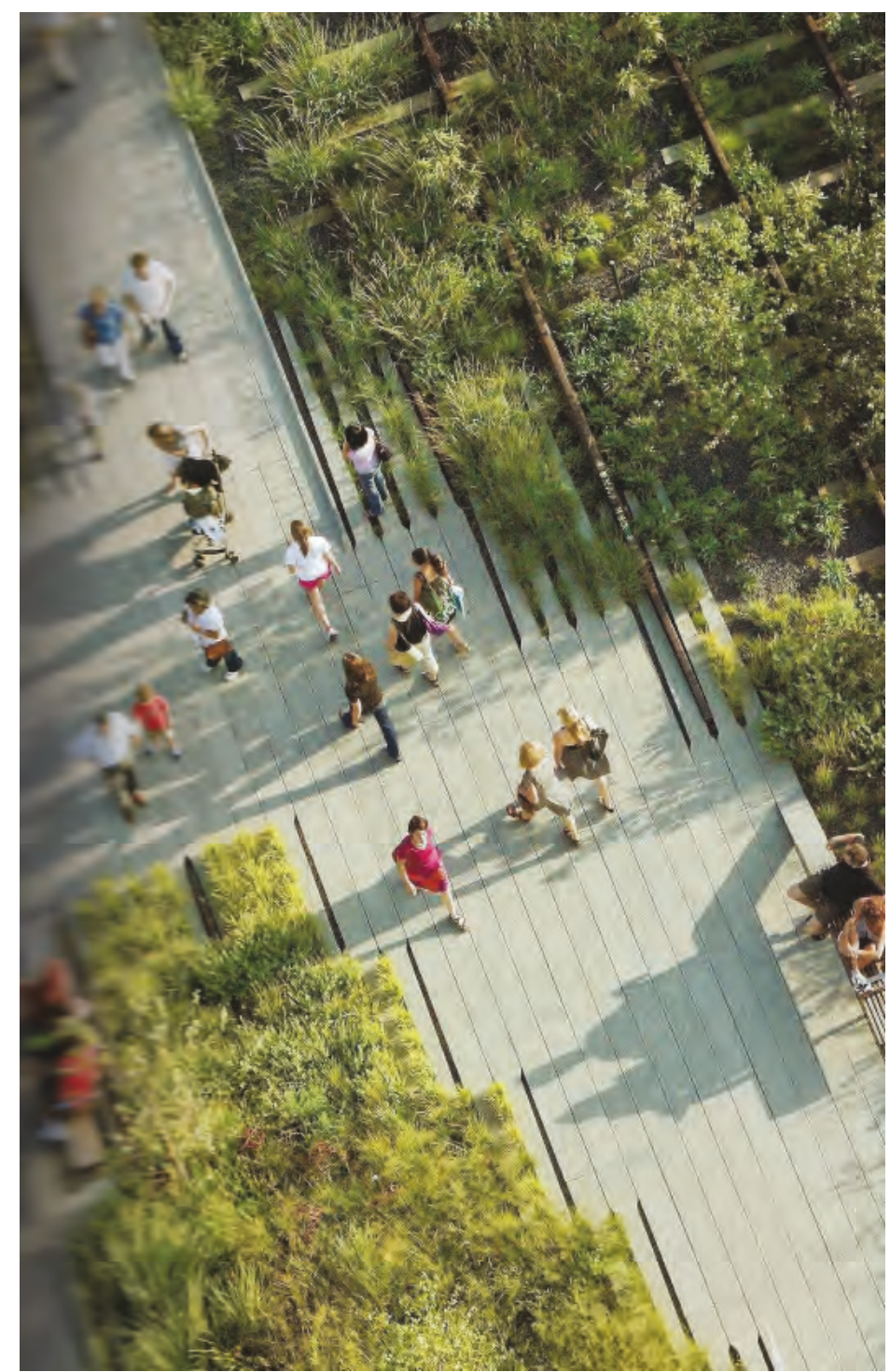

Figure 051 - Park Design - PG 211 - High Line: The inside Story of New York City's Park in the Sky

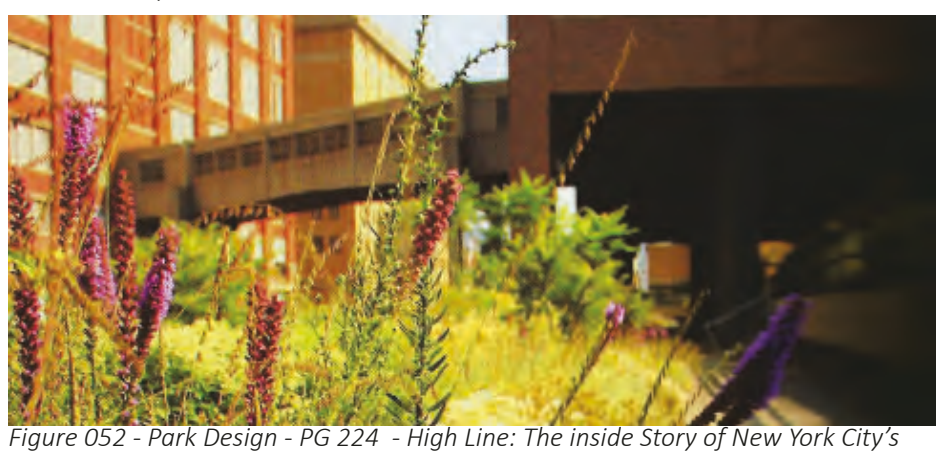
Park in the Sky
High Line

New York, N.Y.

The High Line is a linear park that travels above New York City, on a vacated, elevated railway corridor.

When designing it "Many of the High Line's original railroad tracks were reinstalled into the new landscape tapered concrete plants were put in place, making up the High Line's pathway system.."15 [David, 2011, p.196]

The park gradually changes in landscape, as it progresses through the city. "Here, the park's concrete pathway gives way to the lush grass of the Twenty Third Street lawn. As it continues north, the lawn gently peels up from the surface of the High Line to create a subtly elevation vantage point..."16 [David, 2011, p.250]

Reappropriating an unused space in the city, becomes an asset in the changing urban environment. 


\section{Appendix}

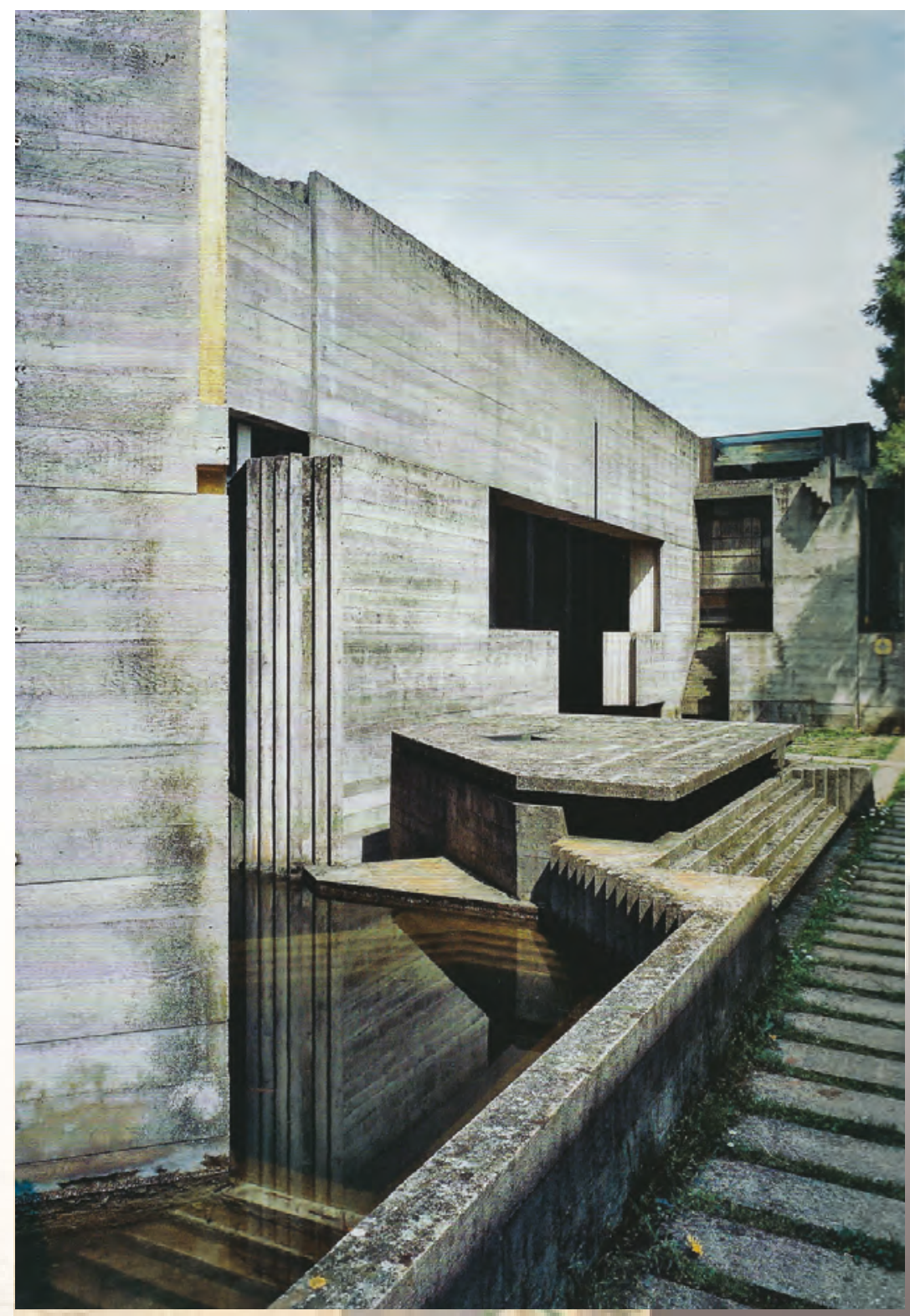

Figure 053 - CARLO SCARPA - IMAGE P.262

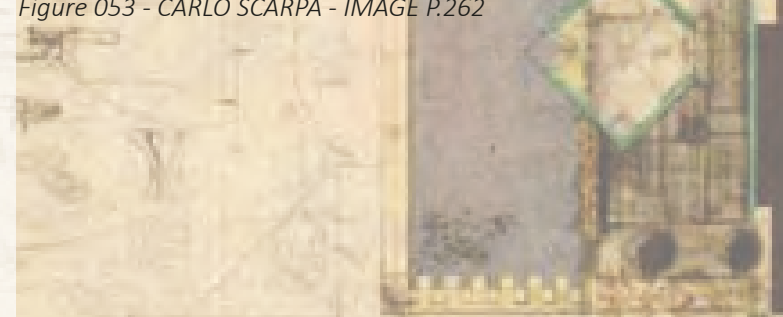

Brion Tomb,

San Vitod' Altivole,

Carlo Scarpa,

1969

"The Brion Cemetery employs the ziggurat Stepping circulation, which, here, is not limited to moldings but are used to give form to the edges and opening of nearly every surface. All concrete surfaces, the cemeteries dominate material, are given the ziggurat stepping articulation, often resulting in pyramidal, V-shaped forms that produce different readings depending on weather they are solid or void, oriented vertically or horizontally."17 [McCarter, 2018, p.240]

Creating edges of a space forms the space, making structure without becoming too formal, creating a flexible space. 


\section{Appendix}

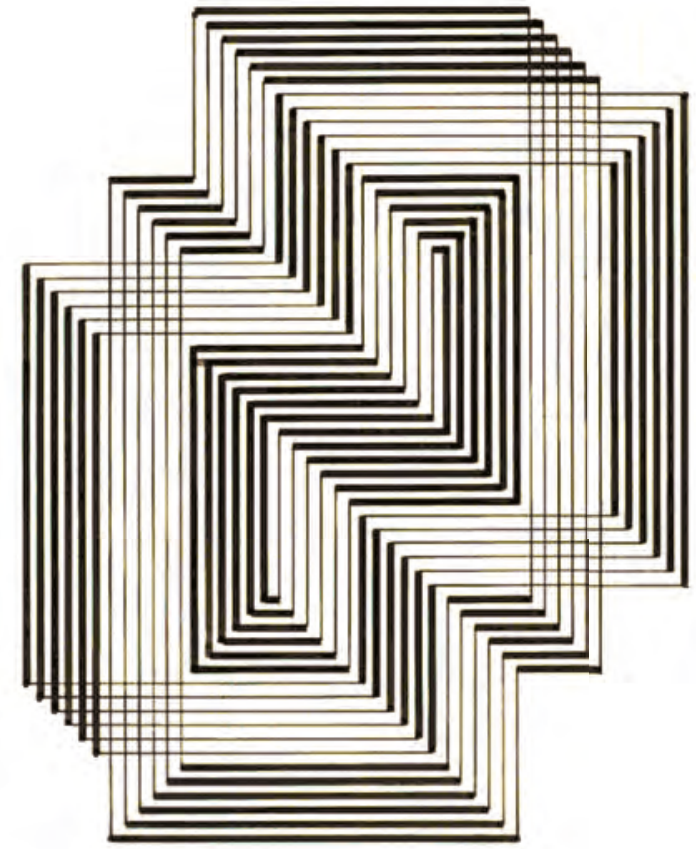

Figure 055 - Josef Albers, Blurred Lines
When I looked at an artwork by Josef Albers, called Blurred Lines I was attracted to this image when looking at public spaces and thinking of it in context to the space between. Public space should be interactive, useful, functional, and interconnect with the city. A public space should incorporate the surrounding areas, and take into consideration the surrounding functions. A space should stretch out and incorporate what is around it and that will help pull people into a shared space, thereby allowing it to become an extension of the community. 


\section{Appendix}

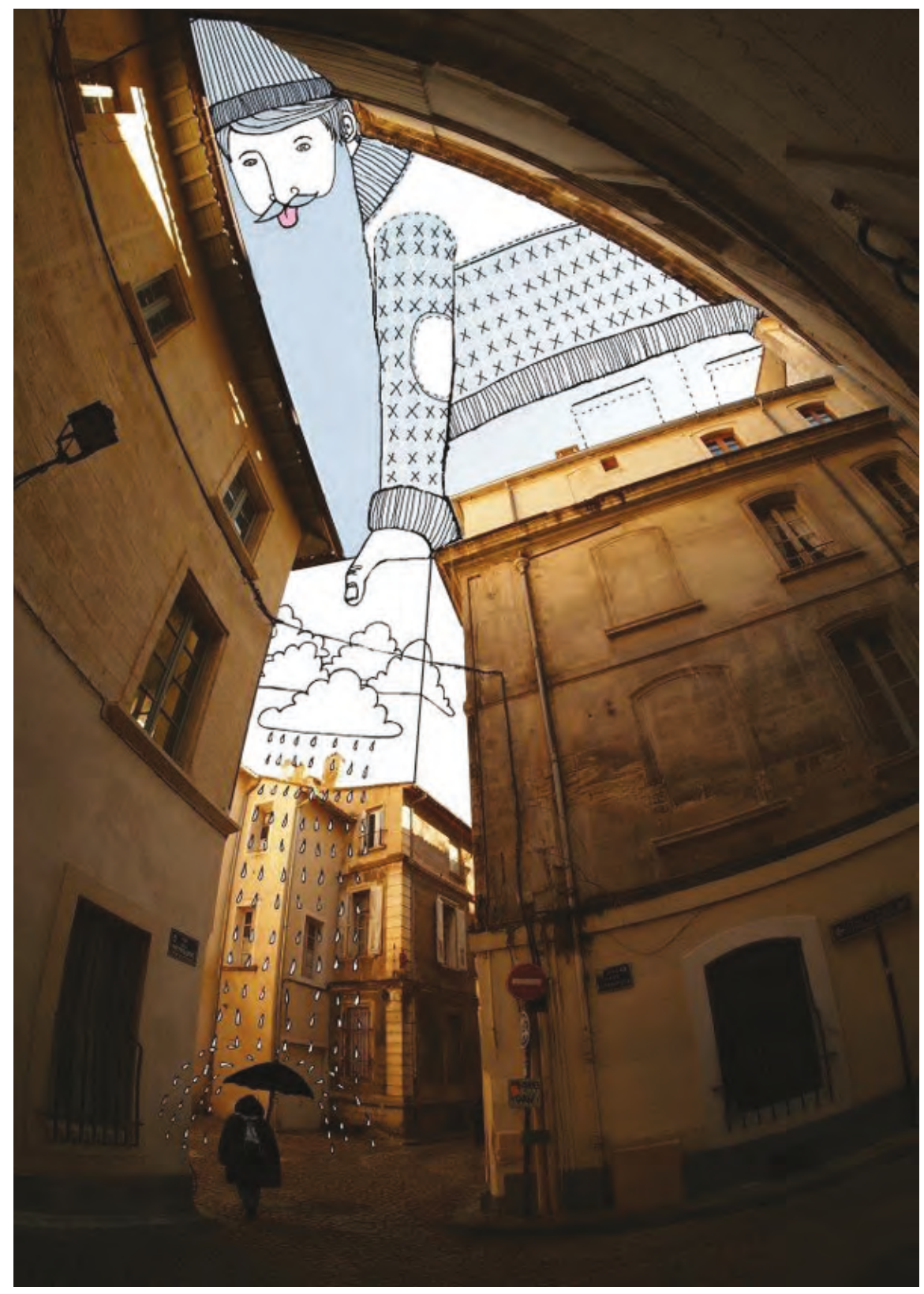

Sky Art Avignon II,

France 2012,

Thomas Lamadieu

He creates images of imagination in between buildings, giving viewers a new perception of urban architecture, helping people see the every day environment in a new way.

It is good to step back and look at spaces from a different perspective. Expanding our imagination and changing perceptions of what space is, and what it can be - applying boundless imagination to the everyday environment. 


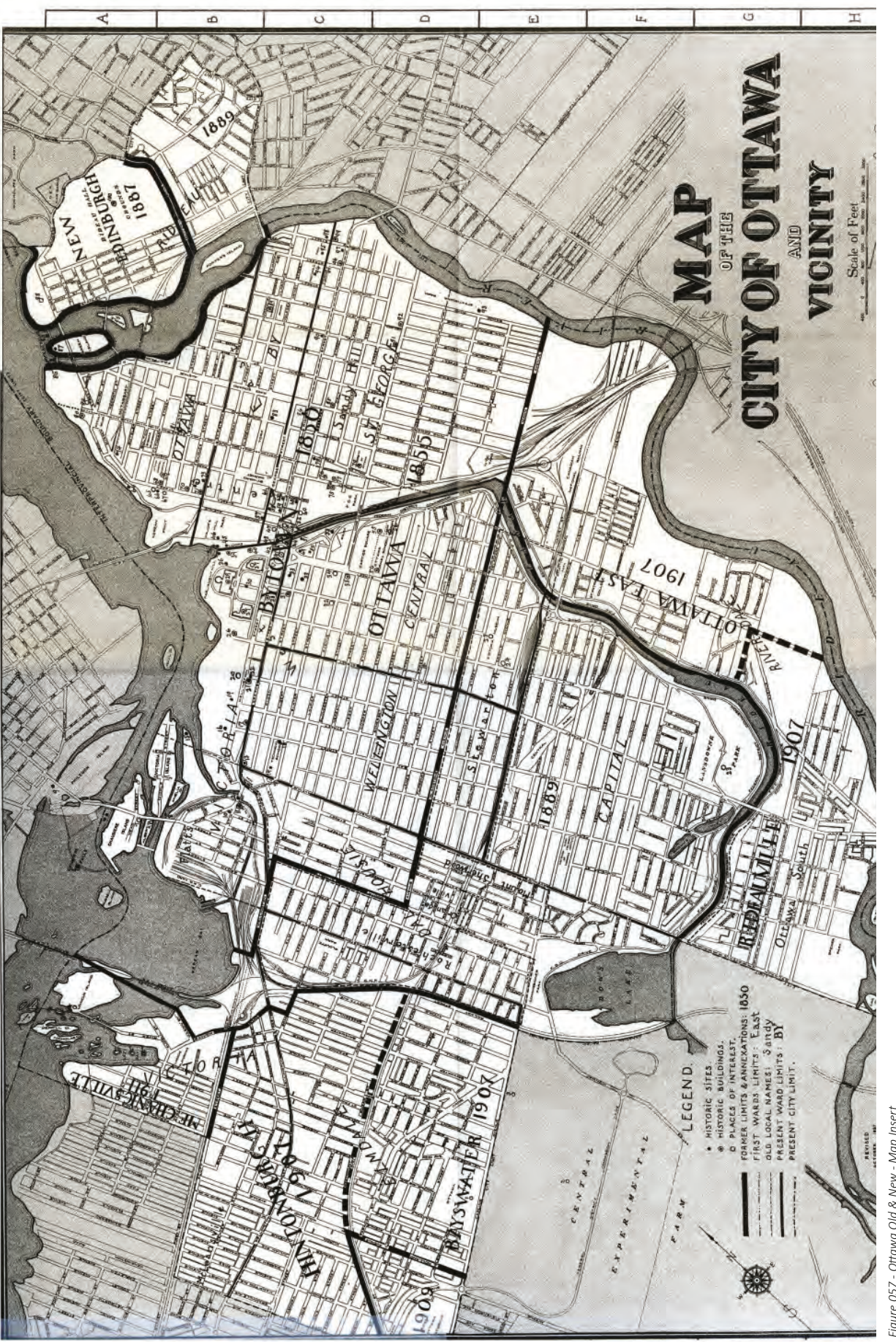

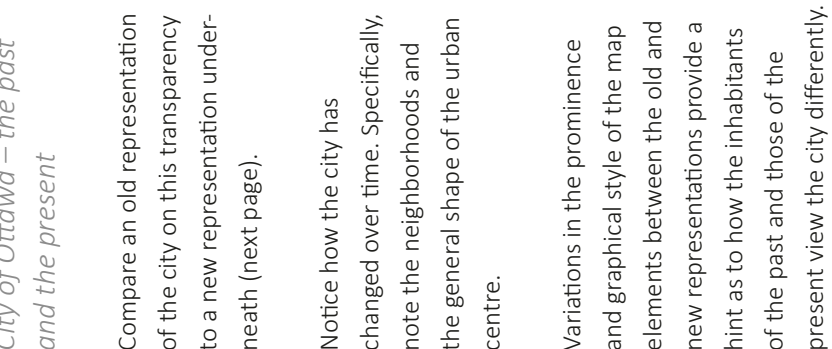




\section{List of Illustrations}

Figure 001- Josef Albers, Blurred Lines \{Blurred Lines; Artistic Drawing- By Josef Albers. [Gardian News and Midia Limited, 2014]\}

Figure 002- Transformation

Figure 003-Transformation

Figure 004- Studentenwohnheim The Street in Mathura Keilförmige Fenstererker mit Nordausrichtung- Image of Building [Sanjay Pur Architects.]

Figure 005- Public Vs. Private

Figure 006- George Mikhail, The 18th Sketch Axonometric \}George Mikhail. The Bridge. [George Mikhail, 2014] The 18 Sketch Aronometric.\}

Figure 007- Complex order V.1. \}Eduard Aquino, and Karen Shanski. Complex order: Introductions in Public Space. [SPMB, 1998] 92.\}

Figure 008- Complex order V.2. \{Eduard Aquino, and Karen Shanski. Complex order: Introductions in Public Space. [SPMB, 1998] 188.\}

Figure 009- Tyson + Billy Architects, Art through fire \{Tyson and Billy Architects. Art Through Fire. [Tyson and Billy Architects, 2011] Photo.\}

Figure 010- City Square

Figure 011- Map of Ottawa

Figure 012- Close up Ottawa Map

Figure 013- Linear Void; Photograph and manipulation by author.

Figure 014- Linear Void- Map

Figure 015- Ghost Space- Photograph 


\section{List of Illustrations}

Figure 016- Ghost Space- Map

Figure 017- Seasonal Space- Photograph

Figure 018- Seasonal Space- Map

Figure 019- Residual Space- Photograph

Figure 020- Residual Space- Map

Figure 021- Blue Space- Photograph

Figure 022- Blue Space- Map

Figure 023- Urban Forest- Photograph

Figure 024- Urban Forest- Map

Figure 025- Adaptability- Image

Figure 026- Elevation- Image

Figure 027- Lighting- Image

Figure 028- Ephemeral Image

Figure 029- A Narrow Height- Photograph and Rendering

Figure 030- Linear Void: Negative and Positive Space- Photograph and Rendering

Figure 031- Concave lens device sectional diagram

Figure 032- Map, and Section of the design of the Ghost Space 


\section{List of Illustrations}

Figure 033- Seasonal Space- Photograph and Rendering

Figure 034- Cut Through, Post Intervention- Photograph and Rendering

Figure 035- Dead End- Design Plan

Figure 036- Dead End- Section Drawing of the Designed Space

Figure 037- Blue Space- Photograph and Rendering

Figure 038- Plan Sketch of the New Circulation of the Space

Figure 039- MAP of the Overall Design

Figure 040- Sketch of the New Circulation of the Space

Figure 041- Continuous Path- Photograph and Rendering

Figure 042- MAP of the Urban Forest Design

Figure 043- Urban Forest- Photograph and Rendering

Figure 044- Alternative Transformations

Figure 045- Photo 1979

Figure 046- Photo 2014

Figure 047- Image from geo ottawa - 1965

Figure 048- Image from geo ottawa - 2015

Figure 049- Park Design

Figure 050- Park Design 


\section{List of Illustrations}

Figure 051- Park Design- PG 211 - High Line: The inside Story of New York City's Park in the Sky

Figure 052- Park Design- PG 224 - High Line: The inside Story of New York City's Park in the Sky

Figure 053- CARLO SCARPA- IMAGE P.262

Figure 054- CARLO SCARPA- IMAGE P. 241

Figure 055- Josef Albers, Blurred Lines

Figure 056- Thomas Lamadieu known as 'Sky Art' - 2012

Figure 057- Ottawa Old \& New- Map Insert

Figure 058- Ottawa Street Map 


\section{Endnotes}

1 Eduard Aquino, and Karen Shanski. Complex order: Introductions in Public Space.[SPMB, 1998] 19.

2 Elizabeth M. Grierson. Transformations: Art in the City. [Bristol: Architec ture_Media_politics_Society (Amps), 2017 ] vii.

3 Elizabeth M. Grierson. Transformations: Art in the City. [Bristol: Architec ture_Media_politics_Society (Amps) , 2017 ] 5.

$4 \quad$ Mark Kigwell and Patrick Turmel. Rites of Way: The Politics and Poetics of Public Space. [Toronto: Wilfrid Laurier University Press, 2009] 75.

5 Jan Gehl. Life between Buildings: using public space. [The Danish Archi tecture Press, 2006] 9.

$6 \quad$ Bill Hillier. Space and spatiality: what the built environment needs from social theory. [Building Research \& Information, 2008] 221.

$7 \quad$ Eduard Aquino, and Karen Shanski. Complex order: Introductions in Public Space. [SPMB, 1998] 92.

8 Eduard Aquino, and Karen Shanski. Complex order: Introductions in Public Space. [SPMB, 1998] 188.

9 Cable Space. The Value of Public Space. [Cable Space, 2003] 12.

10 Eduard Aquino, and Karen Shanski. Complex order: Introductions in Public Space.[SPMB, 1998] 19.

11 Elizabeth M. Grierson. Transformations: Art in the City. [Bristol: Architec ture_Media_politics_Society (Amps), 2017 ] 3.

12 Juan J. Tuset. Peter Shepheard: Spaces in Between the Architecture and the Landscape. [2016] 151.

13 Elizabeth M. Grierson. Transformations: Art in the City. [Bristol: Architec ture_Media_politics_Society (Amps), 2017 ] 21. 


\section{Endnotes}

14 Elizabeth M. Grierson. Transformations: Art in the City. [Bristol: Architec ture_Media_politics_Society (Amps), 2017] 3.

15 David Joshua and Robert Hammond. High Line: The Inside Story of New York City's Park in the Sky. [Farrar, Straus, and Giroux, 2011] 169.

16 David Joshua and Robert Hammond. High Line: The Inside Story of New York City's Park in the Sky. [Farrar, Straus, and Giroux, 2011] 250.

17 Robert McCarter. Carlo Scarpa. [Phaidon Press Ltd. 2018] 240. 


\section{Sources}

Aquino, Eduardo, and Karen Shanski. Complex order: Introductions in Public Space. SPMB, 1998.

ArchDaily. The Street / Sanjay Puri Architects . November 16, 2017. https:// www.archdaily.com/office/sanjay-puri-architects (accessed November 14, 2018).

Arendt, Hannah. The Human Condition. Chicago: University of Chicago Press, 1958.

Barrera, Mario González. Ephemeral architecture. December 29, 2012. http:// portfolios.pratt.edu/gallery/6469205/Ephemeral-architecture (accessed November 3, 2018).

Baunetz Wissen. Janurary 2017. https://www.baunetzwissen.de/sonnenschutz/ objekte/wohnen/studentenwohnheim-the-street-in-mathura-5437606 (accessed December 10, 2018).

Borasi, Giovanna, and Mirko Zardini. Actions: What You Can Do With the City. Montreal; Amsterdam: Canada Center for Architecture; SUN, 2008.

Brigitte Shin, Donald Chong. Site Unseen: Laneway Architecture and urbanism in Toronto. Toronto: University of Toronto Faculty of Architecture and landscape design, 2004.

Cable Space. The Value of Public Space. London, 2003.

Chow, Mel Ling. Urban dialysis: [re] invigorating urban vitality using adhocism. 2012.

City of Ottawa. geoOttawa. 2019. http://maps.ottawa.ca/geoOttawa/ (accessed March 12, 2019).

Citybreak. Le Jardin du Luxembourg. 2018. http://blog.citibreak.com/jar din-du-luxembourg/ (accessed March 14, 2018).

Cranz, Galen. The Politics of Park Design. Cambridge, Massachusetts: The MIT Press, 1982. 


\section{Sources}

decomg. Home And Building Natural Light Design And Architecture 53. n.d. https://decomg.com/80-amazing-home-and-building-natural-light-ar chitecture-design/home-and-building-natural-light-design-and-archi tecture-53/ (accessed November 8, 2018).

DeKAY, Mark. Integral Sustainable Design: Transformative Perspectives. London: earthscan, 2011.

Elborough, Travis. A Walk in the Park. London: Jonathan Cape, 2016.

El-Khoury, Rodolphe, and Edward Robbins. Shaping the City: Studies in History, Theory and Urban Design. New York; London: Routlege: Taylor \& Francis Group, 2013.

Emily Carr Institute. Architypes. Vancouver: Charles H. Seott Gallery, 2004.

Enpundit- art \& design site. n.d. http://enpundit.com/thomas-lamadieus-sky-artinvolves-whimsical-drawings-in-the-space-between-buildings/ (accessed December 10, 2018).

Ford, Larry R. The Space between Buildings. Baltimore, Maryland, USA, 2000.

Gehl, Jan. Life between Buildings: using public space. The Danish Architecture Press, 2006.

Gibson, Eleanor. Dezeen. September 10, 2016. https://www.dezeen. com/2016/09/10/prototype-square-mailitis-aiim-timber-pavilion-old-ce sis-brewery-latvia/ (accessed October 23, 2018).

Grierson, Elizabeth M. Transformations: Art in the City. Bristol: Architecture_Me dia_politics_Society (Amps) , 2017.

Guardian News and Media Limited. Blurred lines: Josef Albers' rare black and white drawings - in pictures. May 6, 2014. https://www.theguardian. com/artanddesign/gallery/2014/may/06/blurred-lines-josef-albersblack-and-white-drawings-in-pictures\#img-8 (accessed September 18, 2018). 


\section{Sources}

Hawkes, Dean. The Environmental Imagination. New York: Routledge, Taylor \& Francis Group, 2008.

Hillier, Bill. "Space and spatiality: what the built environment needs from social theory." Building Research \& Information, 2008: 216-230.

IDENSITAT ID. ZOMBIE SPACES | URBAN TEMPORALITIES . 2017. https://www. idensitat.net/en/zombie-spaces/1348-zombie-spaces-urban-temporali ties (accessed October 8, 2018).

Joshua David, Robert Hammond. High Line: The Inside Story of New York City's Park in the Sky. New York: Farrar, Straus, and Giroux, 2011.

Kigwell, Mark, and Patrick Turmel. Rites of Way: The Politics and Poetics of Public Space. Toronto: Wilfrid Laurier University Press, 2009.

Knabb, Ken. Situationist International: Anthology (Revised and Expanded Addi tion). Bureau of Public Secrets, 1953.

Lamadieu, Thomas. Sky Art. n.d. https://www.thomaslamadieu. com/skyart/ (accessed July 13, 2019).

Laquerre, Alexandre. Ottawa Past \& Present. July 20, 2014. http://www.pastotta wa.com/comparison/courtyard-clarendon-lane-part-ii/454/ (accessed November 16, 2018).

Lucien Brault, M.A., P.H.D. Ottawa, Old \& New. Ottawa: Ottawa Historical Infor mation Institute, 1946.

McCarter, Robert. Carlo Scarpa. New York : Phaidon Press Limited, 2013. Mikhail, George. THE BRIDGE . June 28, 2014. http://gmikhail.blogspot. com/ (accessed October 23, 2018).

Miller, Kristine F. Designs on the Public. Minneapolis: University of Minnesota Press, 2007.

Nagle, Aubrey. Plans for Roxborough's new pocket park unveiled. August 7, 2015. https://www.phillyvoice.com/plans-roxboroughs-new-pocket-park-un veiled/ (accessed December 10, 2018). 


\section{Sources}

Tyson and Billy Architects . Art through Fire. September 28, 2011.

https://tysonandbilly.com/art-through-fire/ (accessed November 16, 2018).

Rose, Jeff. "This Place is about the Struggle." Io Squaderno No. 30, December 2013: 47- 50.

Roxborough Pocket Park. n.d. https://roxboroughpa.com/enjoy-the-outdoors/ roxborough-pocket-park (accessed July 13, 2019).

Schein, Rebecca. "Whose Ocupation? Homelessness and the Politics of Park Encampments." Social Movement Studies: Journal of Social, Cultural, and Political Protest, Augest 6, 2012: 335-341.

Spacey, John. 10+ Types of Public Space. May 5, 2016. https://simplicable.com/ new/public-spaces (accessed September 18, 2018).

Stevens, Quentin. The Ludic City: Exploring the Potential of Public Spaces. New York: Routledge Taylor and Francis Group, 2007.

Tuset, Juan J. Peter Shepheard: Spaces in Between the Architecture and the Landscape. 2016. http://polired.upm.es/index.php/proyectos_arquitec tonicos/article/viewFile/3065/3136 (accessed September 20, 2018).

Vidiani.com. Ottawa Road Map. 2011. http://www.vidiani.com/large-road-mapof-central-part-of-ottawa-with-street-names/ (accessed July 13, 2019).

Whitney North Seymour, Jr. Small Urban Spaces. New York: New York University Press, 1969. 